Title: Performance Criteria-based Effect Size (PCES) Measurement of Single-case Experimental Designs: A Real-World Data Study

Running Head of The Manuscript: Performance Criteria-based Effect Size Measurement of SCEDs

Authors: Orhan Aydin'1, René Tanious²

${ }^{1}$ Corresponding Author, Research Institute for Individuals with Disabilities, Anadolu University, 26470, Eskişehir/Turkey, E-mail: o_aydin@anadolu.edu.tr, Telephone: +90 05346638868

${ }^{2}$ Methodology of Educational Sciences Research Group, KU Leuven, Leuven, Belgium. Tiensestraat 102, 3000 Leuven, PO Box 3762. E-mail: rene.tanious@,kuleuven.be, Telephone: $+3216328219$ 


\title{
Performance Criteria-based Effect Size (PCES) Measurement of Single- case Experimental Designs: A Real-World Data Study
}

\begin{abstract}
Visual analysis and nonoverlap-based effect sizes are predominantly used in analyzing single case experimental designs (SCEDs). Although they are popular analytical methods for SCEDs, they have certain limitations. In this study, a new effect size calculation model for SCEDs, named performance criteria-based effect size (PCES), is proposed considering the limitations of four nonoverlap-based effect size measures, widely accepted in the literature and blend well with visual analysis. In the field test of PCES, actual data from published studies were utilized, and the relationship between PCES, visual analysis, and the four nonoverlap-based methods was examined. In determining the data to be used in the field test, 1,012 tiers ( $\mathrm{AB}$ phases) were identified from four journals, which have the highest frequency of SCEDs studies, published between 2015 and 2019. The findings revealed a weak or moderate relationship between PCES and nonoverlap-based methods due to its focus on performance criteria. Although PCES has some weaknesses, it promises to eliminate the causes that may create issues in nonoverlap-based methods, using quantitative data to determine socially significant changes in behavior and complement visual analysis.
\end{abstract}

Keywords: Single-case experimental designs, acceptable performance criteria, mastery criterion, effect size, social validity, nonoverlap-based effect sizes 


\section{Introduction}

Single-case experimental designs (SCEDs) are a group of experimental designs that facilitate the evaluation of causal or functional relationships between dependent and independent variables for a single entity (Kratochwill et al., 2010; Maggin et al., 2017; Maggin \& Odom, 2014; Tekin-Iftar, 2018). They are extensively used in psychology, clinical disciplines, behavior analysis, and special education (Vlaeyen et al., 2020, Kazdin, 2021). In addition, they are increasingly employed in the field of medicine and rehabilitation (Janosky et al., 2009; Tate \& Precides, 2019). With the dissemination of SCEDs, many suggestions have been offered on how to analyze them (Shadish, 2014). Although the predominant method is visual analysis (Kazdin, 2021), many researchers maintain that practitioners working with SCEDs should not rely solely on visual analysis and consider quantitative analysis such as effect size measures to determine the effectiveness of interventions (e.g., Harrington \& Velicer, 2015; Kratochwill et al., 2014; Manolov \& Vannest, 2019; Shadish et al., 2015; Vannest \& Ninci, 2015). Today, the sole use of visual analysis is discouraged due to low interrater reliability (Brossart et al., 2014; Kratochwill et al., 2014; Shadish, 2014). Therefore, it is widely accepted that visual analysis coupled with statistical methods such as effect size estimates or inferential statistics, along with incorporating randomization, increases the validity, reliability, and acceptability of evaluations of SCEDs interventions (Brossart et al., 2014; Kratochwill et al., 2014; Manolov et al., 2014; Shadish, 2014; Tanious et al., 2019; Tanious \& Onghena, 2019).

The most commonly used quantitative method in the statistical analysis of SCEDs are nonoverlap-based effect size methods (Jamshidi et al., 2018; Maggin, O’Keffe, et al., 2011). Nonoverlap-based measures are typically free of statistical assumptions such as sample size, normality, and constant variance (Brossart et al., 2014). They are simple, can be calculated by hand in a short time, and are easy to interpret (Manolov \& Moeyaert, 2016). In addition, there 
is consensus among researchers that nonoverlap-based indexes are a supplement to visual analysis (Manolov \& Moeyaert, 2016; Parker et al., 2011a). Therefore, they are the most preferred methods along with visual inspection for data analysis in SCEDs (Jamshidi et al., 2018; Maggin, O’Keffe, et al., 2011; Manolov \& Moeyaert, 2016).

Although the nonoverlap-based effect sizes are the most used indexes in single-case data analysis, compatible with visual analysis, and easy to calculate, all of them have some unresolved and common problems (Carlin \& Costello, 2018; Ferron et al., 2020; Wolery et al., 2010), which inspired the development of the present method. First, they cannot distinguish whether the amount of improvement in an individual's performance with introducing intervention is clinically significant (i.e., social validity of the behavior change). Second, when a minimal improvement is achieved compared to baseline, if no overlap across phases, the intervention would be considered highly effective according to nonoverlap-based effect sizes. Alternatively, in the presence of outliers, even if a great improvement is achieved, the intervention would be evaluated as ineffective. Third, the nonoverlap indices cannot determine the improvement change differences for the data patterns that do not overlap but have improved at different levels. This study focuses on an effect size model that eliminates these unresolved limitations. For this, the proposed method suggests evaluating an intervention's effect size according to performance criteria. Before introducing the present method, it is useful to discuss the concept of "acceptable performance criteria" in SCEDs.

\subsection{Description of "Acceptable Performance Criteria (AP-C)"}

Baer et al. (1968) argued that a tactic useful in assessing an intervention's effect on behavior would require questioning not only change in behavior but also who exhibits the behavioral change. Therefore, we can state that the inclusion of information on the extent of the behavioral change in individuals and their characteristics in the evaluation hypothesis may offer a more precise inference in determining whether the intervention has been successful. 
We can term the significance level of behavior change for an individual as "acceptable performance criteria (AP-C)" concept. While determining an AP-C, the extent to which an individual needs the behavior in daily activities and the extent to which the individual should learn the target behavior to teach the subsequent behavior is needed to consider (Umbreit et al., 2007). Besides, the initial performance and competencies of individuals should be considered to set an AP-C. Therefore, we can clearly define that an AP-C is a criterion determined according to the characteristics of "an individual and a skill." On the other hand, in the literature, researchers, clinicians, and educational practitioners have focused generally on the mastery criterion in determining the significance of behavior change.

The mastery criterion (M-C) indicates that the skill has been acquired, and the intervention phase can be terminated (Fienup \& Brodsky, 2017; Fuller \& Fienup, 2018; McDougale et al., 2019). In the M-C, a level of $80 \%$ or above is usually sought for the performance, and it is tested if the skill can be exhibited at a "mastered" level for one to three sessions (Fuller \& Fienup, 2018; Richling et al., 2019). Although an M-C is clearly written in studies, an exact criterion for the AP-C is not specified, or the M-C is considered the same as AP-C. In fact, no data are provided on the M-C in some studies (e.g., Bambara et al., 2018; Bradshaw et al., 2017; Cheng et al., 2015; Wichnick-Gillis et al., 2019). In some cases, the AP-C and M-C may overlap. For example, for a child who is taught the skill of crossing the road safely in traffic, M-C and AP-C are perfect fulfillment of the skill at all levels. However, in some cases, the AP-C and M-C may not overlap. For example, the AP-C will be different for a child who gives five correct answers and for a child who gives one correct answer to 10 single-digit addition problems according to the baseline average. This criterion might be 10 out of 10 for the first child and six out of 10 for the second. Therefore, we can state that due to the different characteristics and baseline levels of each child, a practitioner's effect size expectation for the same intervention will be different per child. So, fulfilling an AP-C 
emerges as a major factor that needs to be considered during an intervention process. In this case, we should consider the AP-C as a mainstay for an intervention's effect size calculation.

The determination of the AP-C may be subjective in nature because this aspect relies more on the practitioners. If an AP-C is not solely determined by the practitioner but also based on several experts' opinions, this can help reduce the subjectivity. Additionally, a performance criterion satisfying about $80 \%$ of the M-C, except for damaging cases (e.g., disruptive, self-injurious behaviors, drug addiction) and safety skills (e.g., some traffic rules, stove burning), can be acceptable. According to Ferron et al. (2020), different methods, namely, (a) targeting the maximum (for increased behaviors) or minimum (for decreased behaviors) values of the scale; (b) targeting the performance of the peers with typical development; and (c) determining the goal line according to expert judgments, can be used to evaluate the behavior change. To set a more objective AP-C, we can employ any of the proposed three approaches by Ferron et al. and two previously mentioned approaches.

As the applied SCEDs studies generally refer to the M-C, the AP-C concept may be considered the same as the M-C for the time being. For example, Stocco et al. (2017) initially intended a $100 \%$ M-C, but reduced it to $40 \%$ - $60 \%$ because the subjects could not reach the initial M-C. These new criteria may be considered the AP-C, but the authors keep referring to it as M-C. In addition, there are ongoing discussions about determining the M-C (e.g., Fienup \& Brodsky, 2017; Fuller \& Fienup, 2018; McDougale et al., 2019; Richling et al., 2019). Thus, the correct description of AP-C may add additional confusion. For this reason, the M-C set by the applied SCEDs researchers in their studies was regarded as the AP-C in testing the proposed method using actual data. In the present study, based on the AP-C concept, i.e., considering M-C, the performance criteria-based effect size (PCES) method will be discussed. In questioning socially significant behavioral change and identifying the effective interventions that resulted in this change, it is expected that PCES would produce more 
realistic and valid results as opposed to nonoverlap-based effect size measures that can possibly produce misleading results by showing the effect size of interventions artificially high or low due to the unresolved problems.

\subsection{Introducing Performance Criteria-based Effect Size (PCES) Measures}

The PCES methods emerge by inspiring the calculations made with the effect size measurements, including the mean-based methods (e.g., Busk \& Serlin, 1992; Shadish et al., 2014) and the split middle-based methods (e.g., Wolery et al., 2010). An effect size is obtained by considering baseline and intervention data's average or distance in the mean/distance-based methods. Several effect size models have been developed based on mean/distance; the most well-known are based on $d$-statistics.

PCES controls the baseline trend through the split-middle method. In accordance with the split middle method (Tekin-Iftar, 2018; White \& Harring, 1980, Wolery et al., 2010), for PCES baseline trend estimations, the baseline data can be divided into two halves for 4-9 data points or more than two halves for more than nine data points. In other words, the data remaining in the halves is shared as a minimum of two and a maximum of four. New mid-rate lines are determined when there are more than four data in the halve. The median of each half is then determined based on performance values and marked on the mid-date, and the trend line is obtained by joining these median points in an approximate location. To determine the degree of the positive baseline trend, it is needed to estimate the trend effect size, which progresses cumulatively (i.e., the trend momentum over time) throughout the intervention phase (White \& Harring, 1980).

In introducing PCES methods, hypothetical data were used (see Figure 1). Figure 1a shows that there was no baseline trend, while Figure $1 \mathrm{~b}$ shows that there was a positive baseline trend. The effect size calculation process is described step by step based on the graph data and shown on the graph. 
(Insert Figure 1 here)

The effect size calculation of an intervention conducted for a student whose baseline values were $30,30,50,30,30$ and intervention values were $40,50,70,65,80,75,90,100,90,100$, where the AP-C was determined as 80, given in Figure 1a, should be as follows:

1. The mean distance values of the subject's baseline values to the AP-C are calculated: $(80-30)+\ldots+(80-30) / 5=46$ units is the mean distance value of the baseline data to the AP-C. The intervention is expected to achieve a mean improvement of 46 units.

2. The mean of all data in the intervention, including those that remained below the AP-C in the intervention process (i.e., 46 units improvement could not be achieved) and the data values that met or performed above the criterion, is determined in terms of achieving an acceptable performance improvement from the baseline. For the current hypothetical example created for the desired behavior, each intervention raw data are subtracted for values under or equal to the AP-C and determined how far exceed the AP-C for values above the AP-C. These new values are evaluated in terms of meeting the expected improvement value (46 units) obtained in Step 1, and the average amount of improvement by the intervention is then determined: $(46-40)+\ldots+(46+20) / 10=42$ units are the mean improvement amount achieved with the intervention.

3. An effect size value is obtained by dividing the improvement amount achieved with the intervention by the targeted improvement determined at the baseline: $42 / 46=.91$.

4. The PCES method also allows for the inquiry of the immediate effect. When we calculate

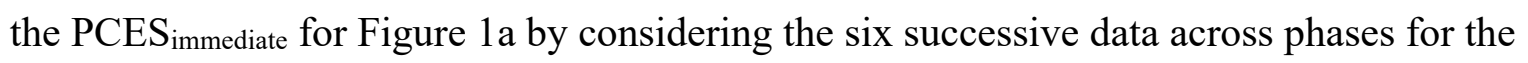
calculation of immediate effect, as recommended by Kratochwill et al. (2010), the mean distance of the last three data points in the baseline to the AP-C is approximately 43 units, and that of the first three data points in the intervention to the AP-C is 27 units. Therefore, the immediate effect was developed by achieving approximately 16 units (43 minuses 27) 
of progress with intervention. As the expected improvement is 46 units, the intervention's immediate effect size is $16 / 46=.35$.

5. If there is a trend in the baseline, as seen in the hypothetical data in Figure $1 \mathrm{~b}$ showing the baseline values as $20,30,40,20,50,40,60$ and the intervention values as $40,50,60,60,80,80,90,100,80,90$ the following steps should be followed:

1. First, the presence of the baseline trend should be visually analyzed based on split middle method. Considering the baseline data in Figure 1b, the mid-rate line is drawn on the fourth session of the baseline data, whereas the mid-date lines are drawn on the second session for the left part of the mid-rate and the sixth session for the right part. The median remaining on the mid-rate's left side is a data point of 30 units, while the median on the right side is determined as 50 units. The determined values are marked on the mid-date line. The baseline trend line is set by combining mid-date line median points remaining on both sides of the mid-rate.

2. If there is a positive baseline linear trend, the effect size is calculated based on the mean distance to the AP-C from the mean of the data points that remain close to the intervention phase from the mid-rate line, i.e., on the rightmost side of the mid-rate lines. According to Figure 1b, the mean of the data that remains on the right side of the mid-rate line $(50+40+60=150 ; 150 / 3=50)$ is 50 units. The AP-C is 80 , and the baseline average is 37 units. Therefore, there is a mean improvement of 13 units (50 minuses 37) with the data set (three data) that remains on the mid-rate line's right side and causes a positive trend. A mean improvement of approximately 43 units is expected. As a result, the effect size of the positive baseline trend is $13 / 43=.30$.

3. The effect size of the positive baseline trend is assumed to be independent of the treatment and continues during the intervention process. Therefore, the mean of the positive trend in 10 data points in the intervention phase (see Figure 1b) should be 
calculated. The calculated positive trend has an effect size of .30 for the three data points, i.e., the data on the right-side of the mid-rate line in Figure 1b, and proceeds cumulatively throughout the intervention. That is, it is assumed that the effect size obtained for the data points on the right-side in the baseline progresses linearly throughout the intervention data points. Therefore, the effect size of the positive baseline trend proceeds through the intervention phase as .30 for the first three successive intervention data points, .60 for the second three, .90 for the third three, and .40 for one of the fourth three. The manipulation rate of the natural effect size on the intervention is obtained as $(.30 \times 3+.60 \times 3+.90 \times 3+.40 \times 1) / 10=.58$. Considering the data in Figure 1b, irrespective of baseline positive linear trend, the intervention's effect size is .83 . However, with an effect size of .58 , the baseline trend manipulates the intervention process as independent of the intervention. Therefore, the refined effect size of the intervention process is calculated as .25.

4. It is crucial to consider the maximum possible performance data in the cumulative improvement of the baseline trend throughout the intervention phase. According to the sample data in Figure 1b, the maximum possible performance will be 100. The maximum possible improvement amount is found to be 63 (100 minuses 37$)$. In this context, the maximum possible effect size is 1.46 (63 is divided by 43). Therefore, the largest cumulative effect size of the baseline trend will be 1.46 . In other words, considering the calculations in Step 5c, if there were 15 or a higher number of data points rather than 10 in the intervention phase in Figure 1b, the cumulative development of the effect size due to the positive baseline linear trend would cease at 1.46 . If we do not take this into account, the cumulative trend effect size calculated for the fifth three successive intervention data points (if there were 15 data points in the intervention) would be 1.50, which would be the value exceeding the maximum effect size limits. 


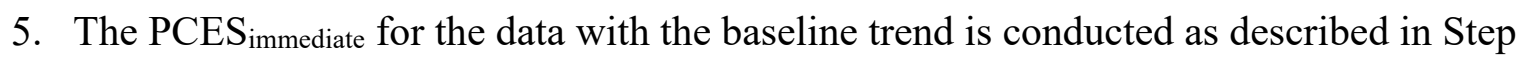
4. However, the positive trend that manipulates the effect (.3) for the first three data points of the intervention should be considered. This value should be subtracted to obtain the pure immediate effect. PCES immediate results in below zero for Figure 1b. Another Similar Method to PCES: PoGO. So far, none of the existing methods for singlecase effect size calculations has sought the clinical significance of the degree of behavior change. However, Ferron and his colleagues proposed a method named percent of goal obtained (PoGO) that pays attention to this point in 2020. This method is described, compared, and calculated as an example here to give the reader an idea due to its similarity to PCES's logic. In brief, PoGO analyzes how close an individual's behavioral level can get to the goal line; thus, the change between the phases can be evaluated according to the goal, and the significance of the change can be questioned (Ferron et al., 2020). PoGO is calculated by dividing the distance from the mean or median value of the baseline to the intervention's mean or median by the distance from the baseline's mean/median to the goal line and multiplying by 100 .

Although PCES and PoGO are similar in terms of examining the significance of the degree of behavior acquisition, PCES is different from PoGO in some aspects. First, while PoGO examines how close the performance to the goal line obtained as an idea, PCES queries it according to the M-C in a behavior analysis fashion. Second, PCES considers a trend equation model (named “cumulative trend”) compatible with visual analysis, whereas PoGO offers that regression-based trend estimations be incorporated in the analysis (but not tested). Third, PCES allows calculating the immediate effect size, but it is not mentioned for PoGO. Fourth, while PoGO constructs the equation with percent, PCES formulates the equation only based on data average. Fifth, PoGO may produce values below 0 and above 100 that are difficult to interpret, whereas PCES values are more suitable and interpretable for effect size 
logic. Sixth, PoGO proposes to consider a stable part of data in baseline and intervention phases for data variability cases (if not considering trend), PCES takes all data into account. Finally, PoGO may expose a limitation for frequency data, but PCES is estimated on all data types for which an AP-C or M-C is set.

Although Ferron et al. (2020) suggest different approaches in PoGO calculations, they consider mean values in their article. They do not assume data trends. Instead, they prefer stable data in the phases with a visual inspection. In addition, they set the goal line according to a maximum or minimum value of scale or level of typically developing peers. Let us make an example calculation for Figures 1a and 1b according to PoGO used in Ferron et al.'s study.

According to Figures $1 \mathrm{a}$ and $1 \mathrm{~b}$, the goal line is 100 for a maximum value (as an idea). In Figure 1a, the baseline data are stable, but the intervention data are not. In this case, the last four intervention data may be considered for PoGO estimate. In Figure 1b, neither baseline nor intervention is stable. It may be suitable to consider data trends. But, Ferron et al.'s examples do not contain trend estimations. They take the stable part of the data into account. In this case, the first five baseline data and the last six intervention data may be considered for PoGO. Accordingly, the PoGO is obtained $92 \%$ and $83 \%$ in Figures $1 \mathrm{a}$ and $1 \mathrm{~b}$, respectively.

The PCES method cannot be compared directly to PoGO due to some uncertainties. For example, it is unclear how PoGO would perform in the presence of trend. PoGO includes subjectivity in the data variability and determining goal line for an independent research. Should PoGO be based on mean or median? These unknowns make it difficult or even impossible to perform objectively PoGO calculations for an independent study. Therefore, a comparison of PCES with PoGO could not be performed in this study. As the development of PCES was inspired by addressing the unresolved issues of nonoverlap-based methods, four commonly used nonoverlap indices in SCEDs analysis were compared to PCES methods for the field test in the present study. 


\subsection{The Aim of Current Study}

The present study aims to test the validity and reliability of the PCES methods by considering the real graphical data in published studies. In this context, the calculations made using the PCES method were compared with nonoverlap-based effect size methods. There are over ten nonoverlap-based methods for analyzing SCEDs. In the current study, four nonoverlap effect size measures were preferred for the field test. Percentage of Nonoverlap Data (PND; Scruggs et al., 1987) is one of the selected ones because it is one of the most frequently used among the SCEDs effect size methods (Jamshidi et al., 2018; Maggin, O’Keeffe, et al., 2011). The other three, Tau- $U$ (Parker et al., 2011b), Improvement Rate Difference (IRD; Parker et al., 2009), and Nonoverlap All Pairs (NAP; Parker \& Vannest, 2009), were selected because they are commonly used in the field and also allow calculation with a web-based computing engine. Besides, PCES calculations were compared with visual analysis results (Lane \& Gast, 2014) on selected graphs. In this context, the following research questions (RQ) were sought: RQ 1: What is the relationship between PCES and the four nonoverlap-based effect sizes? RQ 2: What is the impact of M-C, playing a key role in PCES estimations, on results? RQ 3: Is PCES compatible with visual analysis?

RQ 4: How can PCES values be interpreted?

RQ 5: Can PCES be a practical and realistic guide for researchers and practitioners to determine effective interventions?

RQ 6: Can PCES be used as a valid and reliable index for socially significant behavioral changes?

\section{Method}

\subsection{Data Sources}


The present study sought to rely on real-world data ${ }^{1}$ in testing the effect size. Two inclusion criteria were set to accomplish this task. First, journals were selected based on the review studies conducted by Shadish and Sullivan (2011) and Smith (2012) to determine the characteristics of the SCEDs used in the articles. Four journals that were scanned in both review studies and had the highest SCEDs publication frequency were included to represent real-samples in testing PCES. These journals were Journal of Applied Behavior Analysis (JABA), Research in Autism Spectrum Disorders (RASDs), Journal of Autism and Developmental Disabilities (JADDs), and Focus on Autism and Other Developmental Disabilities (FAODDS).

Second, studies carried out in the five most recent years (January 2015-October 2019) are included in order to keep the sample up to date. The publications from these four journals were downloaded. In total, 2,696 articles were placed into folders. The titles, abstracts, or content of each article were examined, and those incorporating SCEDs were selected. Thus, the total number of articles featuring SCEDs was found to be 406 . Yet certain articles contained several SCEDs, bringing the total number up to 448 . The numbers of the design types obtained from the journals are given in supplemental materials (Table A). Along the same lines with the reviews by Shadish and Sullivan (2011) and Smith (2012), it was found that the published studies mainly incorporated multiple-baseline designs (45.5\%). Of the four journals, JABA published an overwhelming majority of studies with SCEDs (the rate of SCEDs publication being 68\%). For RASDs, the rate of SCEDs studies published declined considerably, and the journal did not publish any SCEDs study in 2017.

\subsection{Data Access Procedure}

\footnotetext{
${ }^{1}$ The information obtained in the data sample was presented as supplemental materials.
} 
To avert any data confusion in the process of testing the PCES methods, certain inclusion criteria were established for SCEDs studies based on literature. These criteria were: (a) only those incorporating multiple-baseline (MB) design as they are the most used design types in the field, $54.30 \%$ and $69 \%$ according to reviews of Shadish and Sullivan (2011) and Smith (2012) respectively, (b) identifying an M-C for skill acquisition in the articles, (c) presentation of the data suitable for visual analysis, and (d) obtaining at least three data in a phase (as suggested by Kratochwill et al. 2010). If there was a tier in which less than three data were provided in a phase within the $\mathrm{MB}$, the tier in question was excluded from the study, but the remaining compatible tiers in the design were included in the testing process.

Based on the established criteria, (a) 204 studies with MB (with a share of 45.5\%), (b) $148 \mathrm{MB}$ studies with openly stated an M-C (72\%), and (c) 140 studies with an evident M-C and which were suitable for visual analysis were determined. From these (see supplemental materials, Table B), 1,012 tiers that met the three or more data point conditions in phase pairing $(\mathrm{AB})$ were obtained. These tiers were included in the further analysis processes. The process flow for obtaining the data to be used for testing PCES is summarized in supplemental materials, Figure A.

\subsection{Data Extraction}

Screenshots of each tier (AB phase) in MB studies that meet the data sample criteria were taken and stored on a computer. Data in the graphs were digitized using PlotDigitizer (http://plotdigitizer.sourceforge.net/), which is a software program with high accuracy and reliability in digitizing single-case graphs (Aydin \& Yassikaya, 2021). After digitizing, decimal numbers were rounded to integers by looking at each graph. The analyses were included 18,479 raw data points. Of these data, $38.5 \%$ belonged to the baseline and $61.5 \%$ to the treatment conditions (for detailed information, see supplemental materials, Table C).

\subsection{Analysis Process}


Nonoverlap-based methods were employed for comparison with PCES, as they were an essential source of inspiration in introducing PCES methods. As previously explained, PND, Tau- $U$, IRD, and NAP were selected because they are more dominant than others in SCEDs analysis.

PND values were calculated based on digitized data by hand. The PND method produces effect size results as percentages. On the other hand, Tau- $U^{2}$, IRD, and NAP analyses were performed using a web-based calculation engine at http://www.singlecaseresearch.org/ developed by Vannest et al. (2016). The IRD, NAP, and Tau- $U$ effect size calculations produced results between 0 and 1 .

All calculations in the PCES methods were performed by hand. The calculation formula mentioned when introducing PCES was used. Thus, the effect sizes were calculated based on the M-C. In brief, PCES can be calculated in three successive equations.

Equation 1 functions to find mean acceptable performence improvement (MAPI):

\footnotetext{
${ }^{2}$ An important note: Positive baseline trend can be controlled in only one of four nonoverlap methods. Tau- $U$ takes into account the monotonic trend in the baseline and offers a calculation with baseline correction. In the Tau- $U$ analysis, A (baseline) and B (treatment) were contrasted either by selecting the baseline correction or without selecting it. However, Parker et al. (2011b) had no clear comment on when to perform the Tau- $U$ analysis with baseline correction. On the other hand, as noted by Brossart et al. (2018): "Parker et al. (2011b) selected a trend level (Tau- $\left.U_{\text {trend }} A\right)$ of .4 noting that Tau- $U_{\text {trend }} A=.4$ represented the $75^{\text {th }}$ percentile in their sample of published data sets that they examined. They only used baseline correction in those data sets where Tau $\geq .40$ in phase A and the Tau-UA vs. B contrast" (p. 9). Therefore, this approach was adopted in the present study to perform baseline correction if the Tau- $U$ value of A contrast was equal to or above .40 . The Tau- $U$ values with and without baseline correction were not grouped separately and not compared with the PCES methods. However, the baseline Tau values were .40 or above in most of the PCES values with trend in the analysis process. In contrast to this, there were few values calculated with Tau- $U$ baseline correction among the data calculated with the PCES values without trend.
} 


$$
\begin{gathered}
a_{i} \bmod 2\left\{\begin{array}{cl}
0: a_{i}-M_{c} ; & a_{i} \geq M_{c} ; \text { increasing or decreasing behaviors } \\
1: M_{c}-a_{i} ; & a_{i}<M_{c} ; \text { increasing or decreasing behaviors }
\end{array}\right. \\
M A P I=\left|\frac{\sum_{i=1}^{n_{A}}\left(a_{\bmod 2=1}\right)-\sum_{i=1}^{n_{A}}\left(a_{\bmod 2=0}\right)}{n_{A}}\right|
\end{gathered}
$$

where $a_{i}=$ each baseline data value, $M_{C}=$ mastery criterion, and $n_{A}=$ number of data points in the baseline phase.

Equation 2 functions to find average-improvement by intervention (ABI):

$$
\begin{gathered}
b_{i} \bmod 4\left\{\begin{array}{c}
0: M A P I-\left(M_{c}-b_{i}\right) ; b_{i}<M_{c} ; \text { increasing behaviors } \\
1: M A P I+\left(b_{i}-M_{c}\right) ; b_{i} \geq M_{c} ; \text { increasing behaviors } \\
\text { or } \\
2: M A P I+\left(M_{c}-b_{i}\right) ; b_{i} \leq M_{c} ; \text { decreasing behaviors } \\
3: M A P I-\left(b_{i}-M_{c}\right) ; b_{i}>M_{c} ; \text { decreasing behaviors }
\end{array}\right. \\
A B I=\frac{\sum_{i=1}^{n_{B}}\left(b_{\bmod 4=0 \text { or } 2}\right)+\sum_{i=1}^{n_{B}}\left(b_{\bmod 4=1 \text { or } 3}\right)}{n_{B}}
\end{gathered}
$$

where $b_{i}=$ each intervention data value, $M_{C}=$ mastery criterion, and $n_{B}=$ number of data points in the intervention phase.

Equation 3 gives PCES effect size calculations:

$$
P C E S=\frac{A B I}{M A P I}
$$

In calculating PCES using trend, if there is a positive baseline trend as per the split middle method, the assumption that the data points carrying the trend have cumulative linearity in the treatment phase as well is considered. The cumulative linearity trend $\left(C_{t}\right)$ equation based on baseline trend is given in the Appendix (for detailed information, see Step 5 in the section describing the method). There should be four or more data in the baseline to determine trend according to the split middle method. However, if the trend is clearly visible in graphs with three data points in the baseline (e.g., 10-20-30), it is assumed that the last two data points of these three data (e.g., consider 20 and 30) carry trend as cumulatively throughout the intervention phase, and the last two data should be considered for calculation of the baseline trend effect. In testing the proposed method with the sampled data, a 
maximum and a minimum number of data points carrying the baseline trend were between two and four. Considering the manipulation of the treatment phase by the positive baseline trend, the calculation of PCES with trend $\left(\mathrm{PCES}_{\text {trend }}\right)$ can be formulated according to

\section{Equation 4:}

$$
P C E S_{\text {trend }}=\frac{A B I}{M A P I}-\mathrm{C}_{\mathrm{t}}
$$

Analysis I: Descriptive Analysis of the Data. The amount of data suitable for comparing the effect size values was determined based on the five methods using data with and without baseline trend in descriptive statistics. The mean and standard deviation of the effect sizes were also calculated. The number of data for which the effect size could not be included due to irrelevant results was determined for each method.

Analysis II: Correlations of the Effect Size Indices. The correlation of the four nonoverlapbased methods was performed using Spearman's rho correlation analysis, whereas their comparison with PCES and PCES trend $_{\text {was }}$ performed using partial correlation. The M-C was assigned as the control variable as it affected the PCES estimation. In addition, scatterplot graphs were generated to illustrate the relationship among the five effect sizes.

\section{Analysis III: Visual Analyses and Effect Size Measurements of Selected Graphs. To}

perform Analysis III, the graphs were determined using four different data models. Two of these were selected from the graphs without trend, namely, the graphical data; (a) that did not overlap but failed to achieve the M-C, (b) that overlapped considerably but satisfied the M-C, whereas the other two were selected from the graphs with trend, namely, (c) in which there was a positive baseline trend but fewer data points in the treatment phase and (d) in which there were baseline trend and more data points in the treatment phase. In performing visual analysis, mean level change, data variability, immediacy effect, and trend direction were considered (Lane \& Gast, 2014). The selected graphical data were analyzed visually, and their 
effect sizes were calculated according to the five methods. In addition, immediate effect size

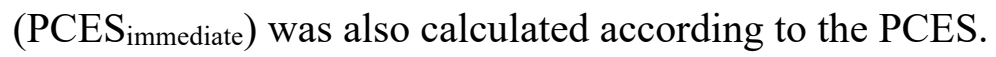

Analysis IV: Discriminability Analysis. According to Parker and Vannest (2009), a new index's usefulness is partially dependent on its ability to distinguish results from the published studies. Effect sizes can be interpreted by quartile distribution analysis obtained from experimental studies (Chen et al., 2019; Solomon et al., 2015; Parker et al., 2011a; Parker \& Vannest, 2009). The current study performed a quartile distribution analysis with a confidence interval of $95 \%$ to analyze the experimental data for PCES. In accordance with Parker et al. (2011a), the quartiles and the 10th and 90th percentile ranks were identified in the creation of percentile distributions, and ways in which the PCES values can be interpreted more precisely were analyzed.

Analysis V: Reliability Analysis and Findings. The present study performed three types of reliability analysis, namely, for (a) the selection of studies based on the M-C, (b) the digitization of graphical data via the PlotDigitizer (with \pm 2 toleration for percentile data), and (c) the effect sizes. In this context, a researcher with knowledge of the targeted analysis assessed $45 \mathrm{MB}$ randomly selected, coded randomly selected 45 articles in terms of the M-C, digitized 51 of 1,012 randomly selected graphs, and performed the effect size calculations (according to the five methods) of 220 randomly selected data. For interrater reliability analysis for the five effect sizes, both kappa and agreement percent analyses were performed. While percent analysis was specified as overall for all data, kappa was calculated separately for all measurements according to the five methods, but effect sizes with/without baseline trend data were not separated. For others ( $a$ and $b$ ), only a percent analysis was performed. According to the inter-rater reliability results, (a) there was an agreement for $\mathrm{M}-\mathrm{C}$ on 43 out of 45 articles (98\%), (b) 908 data were digitized from 51 graphs, and there was a data deviation of $3 \%(n=25)$, (c) the inter-rater percent reliability for the effect size analyses was 
calculated to be approximately $98 \%$ (1084 of 1100). Kappa values for the effect sizes were calculated .98 for PND, .993 for IRD, .986 for NAP, .977 for Tau- $U$ and .981 for PCES (for all, $p<.001)$. Articles, graphs, and effect size calculations were reviewed, and an agreement was obtained in cases of disagreement.

\section{Results}

\subsection{Descriptive Characteristics of Data}

The present study includes $1,012 \mathrm{AB}$ tiers in $\mathrm{MB}$ designs satisfied having at least three data in the baseline and treatment phases and an M-C. Table C (in the supplemental materials) presents the numerical characteristics of these data. As some studies produced results opposite

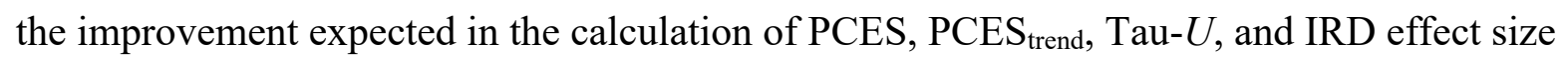
values, they were not estimated and were coded as Nan. For instance, the average of the baseline data in some tiers exceeded or was equal to the M-C (e.g., Montes et al., 2019, Figure 1-Sarah, Lyla). In such a case, the PCES value could not be calculated. Similarly, the PCES value could not be calculated if the average of the data in the intervention phase was below the average level in the baseline phase (e.g., Hassan et al., 2018, Figure 1-Catherine; Kodak et al., 2015, Figure 4-Freddy). Likewise, if the intervention failed to create the desired behavioral change and the treatment performance fell behind the baseline, Tau- $U$ or IRD values produced results in the opposite of the target (e.g., Hassan et al., 2018, Figure 1Catherine; Putnam \& Tiger, 2016, Figure 3- Module 2). To ensure consistency in the calculations, these values were coded as Nan as well. In the web-based calculations, the data exceeding \pm 1 limits for IRD and Tau-U were also obtained. These values were also coded as Nan. In data without baseline trend: 1 of 806 for IRD, 2 of 806 for Tau- $U$, and 5 of 806 for PCES values were coded as Nan.

In PCES trend calculations, the number of the data that could not be calculated was higher. This was because the potential positive baseline trend is shown with linearity. The 
high trend in baseline and an excess number of data points in the treatment resulted in a low

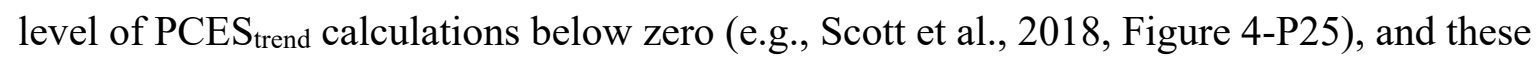
values were also coded as Nan for consistency in the calculations. In data with baseline trend:

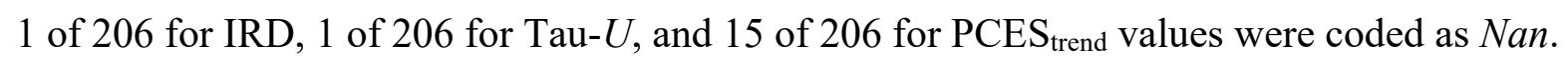

\section{(Insert Table 1 here)}

Table 1 shows the number of tiers with effect size calculations. Accordingly, 800 of 806 tiers without a positive baseline trend provided data suitable for comparison, whereas 190 of 206 tiers with a positive baseline trend produced data suitable for comparison. In analyzing the data without trend, the mean effect size values $\left(\mathrm{M}_{\mathrm{es}}\right)$ were found to be in a range close to each other for the five methods. The $\mathrm{M}_{\mathrm{es}}$ of NAP had the highest mean value with $.93\left(\mathrm{Sd}_{\mathrm{es}}=\right.$ $.12)$, whereas the $\mathrm{M}_{\mathrm{es}}$ of PCES had the lowest mean value $.82\left(\mathrm{Sd}_{\mathrm{es}}=.33\right)$. The PCES calculations had the highest standard deviation in the mean effect size calculations.

In the analysis of data with baseline trend, the mean effect size values were higher for $\mathrm{NAP}\left(\mathrm{M}_{\mathrm{es}}=.94, \mathrm{Sd}_{\mathrm{es}}=.10\right), \operatorname{IRD}\left(\mathrm{M}_{\mathrm{es}}=.84, \mathrm{Sd}_{\mathrm{es}}=.23\right)$, and PND $\left(\mathrm{M}_{\mathrm{es}}=78 \%, \mathrm{Sd}_{\mathrm{es}}=33\right)$ than Tau-U/Tau- $U_{B c}\left(\mathrm{M}_{\mathrm{es}}=.74, \mathrm{Sd}_{\mathrm{es}}=.25\right)$ and $\mathrm{PCES}_{\text {trend }}\left(\mathrm{M}_{\mathrm{es}}=.71, \mathrm{Sd}_{\mathrm{es}}=.54\right)$ which considered the trend. Further, Tau- $U /$ Tau- $U_{B c}$ and PCES $S_{\text {trend }}$ were lower compared with the other three methods that do not consider the trend. The standard deviations of PND and PCES $S_{\text {trend }}$ were estimated to be over 30 units, which was higher compared with the other methods.

\subsection{Correlation Analyses of the Five Methods}

Table 2 presents a matrix for the comparison of the effect size calculations made with and without a trend. For the comparison of the data without trend (Table 2a), PCES had the highest correlation coefficient with NAP $\left(\rho^{\text {partial }}=.63, \mathrm{p}<.0001\right)$ and the lowest correlation coefficient with PND $\left(\rho^{\text {partial }}=.55, \mathrm{p}<.0001\right)$. The correlation between PCES and NAP, PND, IRD $\left(\rho^{\text {partial }}=.62, \mathrm{p}<.0001\right)$, and Tau-U $\left(\rho^{\text {partial }}=.60, \mathrm{p}<.0001\right)$ was 
statistically significant and "moderate." With data without trend, the four nonoverlap methods had a statistically significant and "very high" correlation among themselves $(\rho>.90, p<$ $.0001)$.

\section{(Insert Table 2 here)}

For the comparison of the data with trend (Table 2b), PCES trend $_{\text {had }}$ the highest correlation coefficient with IRD $\left(\rho^{\text {partial }}=.40 \mathrm{p}<.0001\right)$ and the lowest correlation coefficient with PND $\left(\rho^{\text {partial }}=.35, \mathrm{p}<.0001\right)$. The correlation between PCES and IRD, PND, NAP $\left(\rho^{\text {partial }}=.38, \mathrm{p}<.0001\right)$, and Tau- $U /$ Tau $-U_{\mathrm{Bc}}\left(\rho^{\text {partial }}=.38, \mathrm{p}<.0001\right)$ was statistically significant and "weak." For the data with trend, the three nonoverlap methods had statistically significant and "very high" correlation among themselves $(\rho>.90, p<.0001)$, except Tau- $U /$ Tau- $U_{\mathrm{Bc}}$, which had statistically significant and "weak" correlation with IRD $(\rho=.49, \mathrm{p}<.0001)$ and statistically significant and "moderate" correlation with NAP $(\rho=$ $.53, \mathrm{p}<.0001)$ and PND $(\rho=.50, \mathrm{p}<.001)$. Another Spearman's correlation analysis was calculated, but not included in the tables, between PCES values and M-C values. There was a statistically significant and "weak" reverse $(-)$ relationship $(\rho=.33, \mathrm{p}<.0001)$ between PCES and PCES trend $_{\text {and }} \mathrm{M}-\mathrm{C}$ values.

Figure 2 presents the distributional relationship between PCES and PCES trend $_{\text {and }}$ the other four methods. The range of PCES values was between 0 and 2.83. The PCES values were distributed frequently between .5 and 1.2. The three methods' ranges, except NAP (range: $.37-1$ ), were between 0 and 1 . However, the values of nonoverlap-based methods were distributed frequently between .8 and 1 and those for PND between 80 and 100. The range of PCES $\mathrm{S}_{\text {trend }}$ values was between 0 and 4.95. PCES trend $_{\text {values were distributed }}$ frequently between 0 and 1.3. The three methods' value ranges, except NAP (range: $.5-1$ ), were between 0 and 1 . However, the values of nonoverlap-based methods exhibited a frequency distribution between .8 and 1 for NAP, 60 and 100 for PND, .6 and 1 for IRD, and 
.3 and 1 for Tau- $U /$ Tau- $U_{\mathrm{Bc}}$. The M-C distributions were also examined, but Figure 2 does not include them. For the data without trend, the M-C was distributed frequently at the values of 80,90 , or 100 (range: 40-100). For the data with trend, the M-C was distributed frequently at the values of 80 or 90 (range: 66.6-100) as the percent.

(Insert Figure 2 here)

\subsection{Visual Analyses and Effect Size Indices according to Five Methods}

In Figure 3, to illustrate the relationship among visual analysis, four nonoverlap-based methods and PCES, four different real-world data were used, including the graphical data in which (a) there was no overlap, but the M-C could not be achieved (Lerman et al., 2015), (b) there was too much overlap, and the M-C was attained (Fahmie et al., 2016), (c) there was baseline trend, the M-C was attained, and there were fewer data in the treatment phase (Scott et al., 2018), and (d) there was baseline trend, the M-C was attained after a while, and there were more data in the treatment phase (Sherrow et al., 2016).

(Insert Figure 3 here)

As seen in Figure 3a, there was no baseline trend. In addition, the treatment phase data were obtained when the $\mathrm{M}-\mathrm{C}$ was not attained, but there was no overlap in the intervention versus baseline. In this case, even if the target is not attained, the effect size was calculated as $1(100 \%$ for PND) for the four nonoverlap-based methods. In such a case, the intervention was considered "highly effective." However, the intervention effect was minimal (.29) based on the PCES. The PCES method also makes it possible to estimate the immediate effect size. The visual analysis results revealed an immediate effect of approximately $15 \%$. Further, PCES immediate, calculated taking the M-C into consideration, was .17. Therefore, there was a very limited immediate effect. According to the visual analysis results, the mean performance change was $26 \%$ and in the targeted direction. 
As seen in Figure 3b, there was a baseline trend but a negative direction. Accordingly, there was no room for the effect of the intervention to be influenced by the positive baseline trend. In addition, the treatment phase data were obtained when the $\mathrm{M}-\mathrm{C}$ was attained, but there were overlapping data compared with the baseline. In this case, although the target was attained with the intervention at all data, PND produced $0 \%$, NAP was .79, and IRD and Tau$U$ were .59 due to the overlap. The effect of the intervention according to values other than NAP was assessed as "ineffective" or "small effect." Additionally, the intervention was found to be "highly effective" according to the PCES method (PCES =1). Likewise, PCES immediate was considered to be equal to 1 . According to the visual analysis results, the immediacy effect was $65 \%$, and the mean level change was $30 \%$. While the immediate effect change was clear, the mean level change was in the targeted direction and attained the goal.

As seen in Figure 3c, there was a positive baseline trend, and the number of the treatment data was small. The M-C was satisfied (last three data) starting from the baseline phase, and it was even exceeded with treatment. As there was no overlap, the effect sizes were $1\left(100 \%\right.$ for PND) as per the three methods that do not consider the trend. For Tau- $U_{\mathrm{Bc}}$, which considers the trend, the effect size was found to be .65 . However, when the effect size

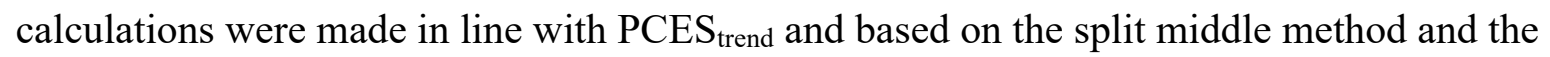

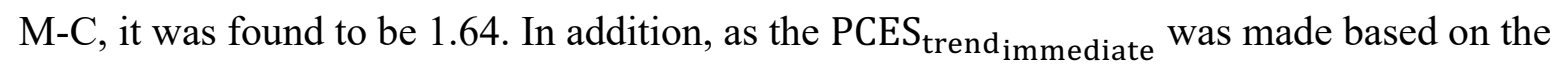
M-C as well as by considering the three successive data across phases, it could not be calculated. According to the visual analysis results, the immediate effect was $15 \%$, the average level change was $22 \%$, and the effect was in the targeted direction.

As seen in Figure 3d, there was a positive baseline trend, and the number of treatment data was high. The effect sizes which not consider the trend were 1 (100\% for PND). For Tau- $U_{\mathrm{Bc}}$, which considers the trend, the effect size was found to be .92 . Further, the PCES $\mathrm{S}_{\text {trend }}$ takes into account the assumption that the manipulation of .06 seen in the last three data in the 
baseline phase progress cumulatively in the treatment phase. Therefore, the PCES value of .76 , calculated without considering the trend, is manipulated with a value of .21 , and the

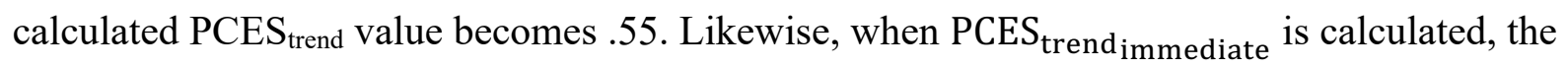
value of .28 is obtained. According to the visual analysis results, the immediate effect was $17 \%$, the average level change was $38 \%$, and the effect is in the desired direction.

\subsection{Interpreting PCES Indices}

The percentile distributions of the values of PCES/ PCES trend $_{\text {and four nonoverlap-based }}$ methods are presented separately in Table 3. In Table 3a, it can be observed that the PCES' high effect for the data without baseline trend might assign $\geq 1.17$; on the other hand, its ineffective value $\leq .39$. Its effective value might assign between 1.02 and 1.17 , whereas its moderate effect between .85 and 1.02. Its small effect might assign between .61 and .85 , and its very small effect between .39 and .61 . The PCES resembles the PND the most among the nonoverlap-based methods in interpreting the data without the baseline trend. These cutoff scores and their interpretations for PCES are presented Table 4.

(Insert Table 3 here)

When Table $3 b$ is examined, it can be observed that the PCES trend $^{\prime}$ high effect for the data with baseline trend might assign $\geq 1.12$; on the other hand, its ineffective value $\leq$. 20 . Its effective value might assign between .92 and 1.12, whereas its moderate effect between .67 and .92. Its small effect might assign between .40 and .67 , and its very small effect between .20 and .40 . The PCES $S_{\text {trend }}$ resembles the Tau- $U /$ Tau $-U_{B c}$ the most among the nonoverlapbased methods in interpreting the data with the baseline trend. These cutoff scores and their interpretations for PCES ${ }_{\text {trend }}$ are presented Table 4.

(Insert Table 4 here)

\section{Discussion}


In the present study, a performance criteria-based effect size calculation model was proposed to determine the effective interventions by addressing certain issues that cannot be resolved using nonoverlap-based methods and questioning whether clinical and educational interventions result in socially significant behavioral changes. As Baer et al. (1968) stressed, questioning socially significant behavioral changes is not a scientific question but a practical one. Therefore, the present study made use of real-life data and performance criteria to test the PCES methods. In testing the PCES methods, the data with and without positive baseline trend were utilized. Further, the split-middle-based PCES trend $_{\text {method, which considered a }}$ positive baseline trend, was proposed.

In the present study, five effect size measurements were analyzed using numerous data models. The correlation among the nonoverlap-based methods was generally high $(\rho>.90, p$ $<.0001)$, whereas their correlation with the PCES methods was moderate or weak. Tau- $U_{\mathrm{Bc}}$

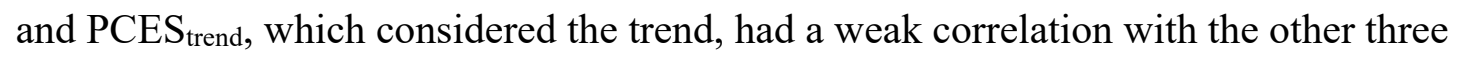
methods. However, their correlation with each other was low, although both considered trend. In general, the correlation between visual analysis and the PCES methods was more significant compared with nonoverlap-based methods. In this section, the analysis conducted using the data with and without trend is discussed separately.

\subsection{Field Test of PCES}

In the data without trend, the correlation of the PCES method with other methods was moderate. The PCES method produced values different from the four nonoverlap-based methods because of the following: (a) outliers (floor or ceiling) constitute a problem in the nonoverlap-based methods, (b) there is no overlap between the baseline and treatment data, but no improvement to the desired level, and (c) even if there is overlap between the baseline and treatment data, M-C is attained or even exceeds with the intervention. 
Comparing the effect sizes of five methods with visual analysis in the data without trend, it can be argued that the PCES method is more compatible. The mean level change, data stability, the targeted direction, and the immediate effect are some of the variables taken into account in the visual analysis (Lane \& Gast, 2014). However, many researchers noted that the visual analysis is subjective (Brossart et al., 2014; Kratochwill et al., 2014; Manolov \& Vannest, 2019; Shadish, 2014). For instance, the trend direction achieved with the intervention may be positive, but the question of the level of this positivity would be unanswered. The mean change in the performance may be small or significant. The amount of change satisfied is another unanswered question. Likewise, it is unclear how much difference is sought between the averages of the three successive data across phases to calculate the immediate effect. The PCES method is based on a criterion to seek these changes between phases. It is a novel method that enables the calculation of the intervention effect based on the

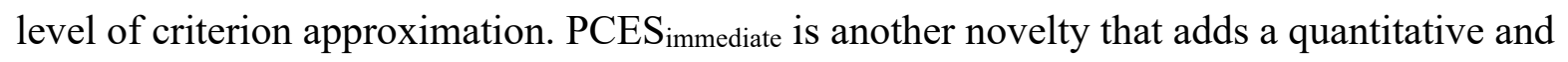
objective assessment to the immediate effects.

In conclusion, even if the nonoverlap based methods fulfill the performance criteria or not, they may produce a very high effect size in the data models without any overlap or a very small effect size in the data models with overlap. On the other hand, the PCES method gives more realistic results on the effectiveness of the intervention by relying on the performance criteria, and it is promising as a method complementing visual analysis.

\subsection{Field Test of PCES trend $_{\text {}}$}

In the data with trend, the correlation of the PCES trend with other methods was weak. The nonoverlap-based effect sizes that did not take the baseline trend generally produced high values if there were no outliers. Unlike such inflated effect size calculations, Tau- $U_{\mathrm{Bc}}$ is a more moderate nonoverlap method. However, while it was unclear when Tau- $U_{\mathrm{Bc}}$ should be implemented, in the present study, baseline correction was made if the contrast of the baseline 
data with each other was in the positive direction and equal to or greater than .40 (as noted by

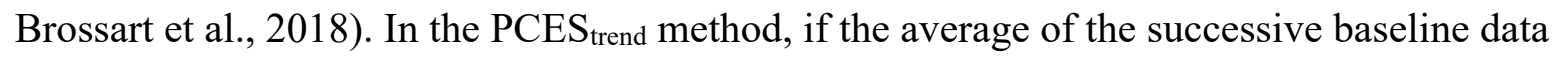
(min. 2 data and max. 4 data) was higher than the average of all data in the baseline phase,

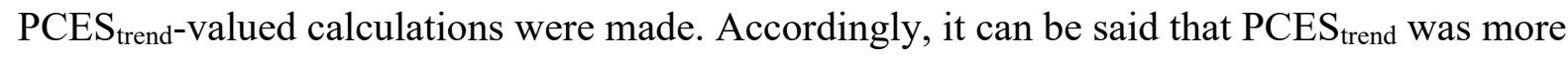
sensitive in terms of considering the trend in the present study.

Although PCES $S_{\text {trend }}$ and Tau- $U_{\mathrm{Bc}}$ considered the baseline trend, the correlation coefficient between the two was considerably low. The most important reasons for this are

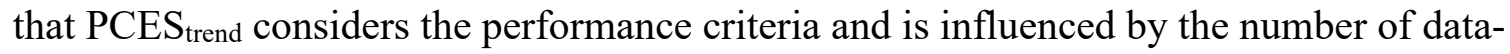
carrying the trend in the baseline phase and the number of data in the treatment phase. Besides, Tau- $U$ analysis relies on monotonic trend, whereas the PCES analysis takes the splitmiddle-based linear trend into account. Contrary to Tau- $U_{\mathrm{Bc}}$ 's closeness to visual analysis (Brossart et al., 2018; Tarlow, 2017), PCES $_{\text {trend's analysis is considerably open and }}$ transparent. Tarlow (2017) indicated that the number of data points in phases influenced Tau$U$ calculations. In the present study, however, the extent to which the number of data points affected PCES $S_{\text {trend }}$ and Tau- $U_{\mathrm{Bc}}$ was not questioned.

The most important problem encountered in the PCES $\mathrm{S}_{\text {trend }}$ was that when the number of data points in the treatment phase was high, the aggregate manipulation of the treatment phase by the positive baseline trend could lower the PCES

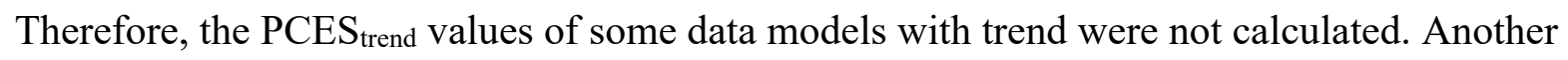
problem was that when the criterion was low and the number of data points in the treatment

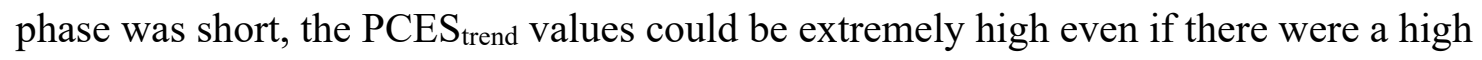
baseline trend. In the present study, PCES trend $_{\text {was }}$ proposed based on the split-middle method. Nevertheless, there are at least five proposed trend methods for single-case data (Manolov, 2018). Therefore, it is possible to adapt different trend calculations to the proposed criteriabased PCES methods. 
Visual analysis of the data with trend considers not only a positive direction but also in the opposite. Also, both the trend in the baseline and those in the treatment are considered (Lane and Gast, 2014). Although Tau- $U$ allows trends in both phases to be considered (Parker et al., 2011b; Tarlow, 2017), only baseline trend is controlled in Tau- $U$. How the intervention trend should be analyzed with Tau- $U$ can be referred to as another "closed box." The PCES $_{\text {trend }}$ considers the positive baseline trend and the state of manipulating the treatment phase. Thus, new equations are needed to interpret the treatment trend with the PCES values.

In this study, percentile ranks were used in the interpretation of experimental data with PCES methods. Although the other four methods' interpretations are clearly described in the literature, a discrepancy prevails when those values are compared to the percentile obtained in this study for them. The reason may be the publication bias (Shadish et al., 2016; Sham \& Smith, 2014) that is the result of journals' publishing only those studies reporting effective results and the researchers' hesitation to report ineffective interventions (Shadish et al., 2016) wherein the percentile rank analyses performed using actual data are affected. Considering this publication bias, it can be suggested that PCES values may be interpreted approximately as Cohen's $d$ values because of more accepted in the literature. In addition, standard errors and confidence intervals can be calculated with the PCES values in accordance with the suggestions of Ferron et al. (2020). This would thus enable more objective interpretations.

As a result, the PCES adopts a different logic compared with many methods in obtaining effect sizes of the data models with and without a trend. M-C was taken as the basis to question the significance of the performance improvement through PCES calculations. A method that produces quantitative values and offers an opportunity for objective assessment for the first time was provided for questioning the socially significant behavior changes, which started to be discussed half a century ago (Baer et al., 1968; Wolf, 1978). 
On the other hand, although PoGO is quite similar to the PCES's logic, there are some conceptual differences. First, the conceptual foundations of PCES have been more comprehensively shaped under the principles of applied behavior analysis (e.g., social validity, mastery criterion). Second, the two methods' computational approaches are different from each other as described previously. Third, PCES was tested with many real-samples data to derive percentile distributions and cutoff scores. Fourth, it was analyzed how the effect size obtained with the PCES could be interpreted. The PCES method is objective and transparent in determining the goal line (i.e., M-C) and executing the calculations. Based on testing practice with a large number of experimental data, the strengths and weaknesses of the PCES methods are listed below.

Strengths of PCES/ PCES trend: (1) PCES is one of the first methods that quantitatively examines socially significant behavioral changes. (2) It is complementary to visual analysis.

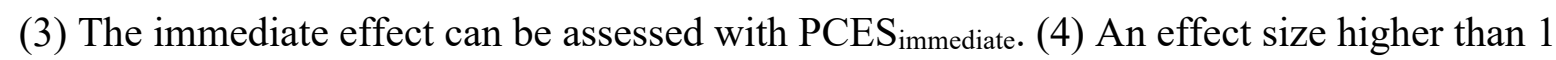
can be obtained in the PCES methods. All improvements by introducing an intervention are considered in the PCES methods. (5) It takes into consideration the positive baseline trend. (6) Its estimation is easy. (7) If a performance criterion is set correctly, PCES offers an objective assessment in helping practitioners reach a clinical judgment. (8) Compared to other methods, its ability to discriminate for treatment effects is relatively high.

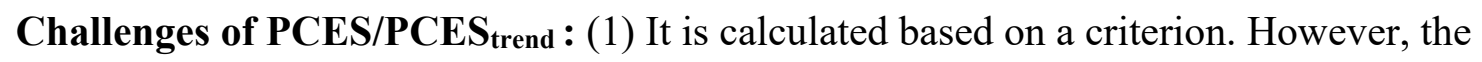
determination of performance criteria (M-C) may be exposed to subjective evaluations of practitioners (Fienup \& Brodsky, 2017; Fuller \& Fienup, 2018; McDougale et al., 2019; Richling et al., 2019). (2) It is influenced by the degree of the criterion. For instance, the highest PCES value for the $100 \%$ performance criteria is 1 , whereas the PCES value for the performance criteria set as 80 over 100 might be 1.25 or more. (3) It is developed based on

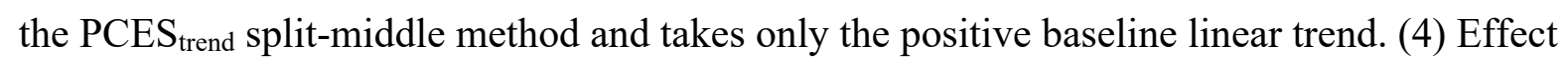


size calculations with PCES $_{\text {trend }}$ are influenced by the number of the data carrying the trend in the baseline phase and the number of the data in the treatment phase. (5) In this study, PCES produces only positive values. It is recommended not to analyze the treatment conditions that make the behavior worse.

In summary, there are many unanswered issues related to nonoverlap-based methods, the most accepted methods in single-case effect size calculations. The common point in all these methods is to determine the presence or absence of overlap or the association in data points between adjacent conditions. Also, in almost all of the effect size methods so far, it has not been questioned whether the intervention has achieved significant improvement in an individual's performance. In determining the actual effect size of an intervention, the requirement of meeting the acceptable performance improvement in the individual should be sought. With a clearer example, the effectiveness of a drug that reduces a patient's fever from $40^{\circ} \mathrm{C}$ to $39.5^{\circ} \mathrm{C}$ is highly questionable. Thus, even if an apparent improvement can be achieved from the baseline by introducing an intervention, it provides insufficient evidence to come to a conclusion about the degree of effectiveness of this intervention.

As a result, an intervention's actual effect size can be determined by calculating an effect size based on an acceptable criterion determined according to the characteristics of "an individual and a skill.” In this study, an effect size calculation method with a rationale based on this approach has been developed. The PCES methods may offer an intermediary way between nomothetic (generalizations over individuals) and idiographic (uniqueness of individuals) assumptions, which have so far been highly debated between visual analysts and quantitative analysts in statistics (Shadish, 2014). Practitioners can determine more reliably whether interventions are effective by calculating their effect sizes with this method, and they can examine the contributions of these interventions to student success with quantitative analysis. Researchers can also use the PCES methods in meta-analysis studies that question 
the generalizability of interventions to individuals or other conditions. The PCES may not be perfect for calculating the effect sizes of single-case data, but its logic is considerably promising. More sensitive and sophisticated criteria-based indexes may be developed, taking into consideration the weakness of PCES analyses.

\subsection{Limitations and Recommendations}

In the present study, the limitations encountered with testing PCES and suggestions for them can be listed under six themes. First, the performance of PCES was tested only with MB designs, which are the most used in the field. However, PCES allows analysis of other designs as well. For the reversal designs such as $A_{1} B_{1} A_{2} B_{2}$, comparing $A_{1}$ versus $B_{1}$ ve $A_{2}$ versus $B_{2}$ can be made based on criteria. With this comparison, the average PCES value can be obtained within the participant. For the multielement designs such as $\mathrm{AB}_{1} \mathrm{C}_{1} \mathrm{~B}_{2} \mathrm{C}_{2}$, considering the baseline (A), A-B $1, A-C_{1}, A-B_{2}$, and $A-C_{2}$ can be contrasted, the average PCES can be obtained and compared for B and C interventions.

Similarly, as in some studies (e.g., Aydin \& Diken, 2020; Satsangi et al., 2020), for alternating treatment designs, if baseline data is available, the treatments' performance can be compared to each other. When PCES is employed, the treatments can be compared based on criteria. If baseline data is not exhibited in these designs, PCES calculations would be difficult like other methods. However, reporting the initial performance of behavior through natural observations may be a resource for PCES measures. As a note, the carry-over effect might be a problem that should not be neglected for all effect size types in comparative designs. Apart from them, for changing-criterion designs, the average PCES can be obtained by considering each step's criteria and contrasting baseline versus criteria. Further research should seek how PCES performs in different single-case designs.

Second, according to the study sample result, M-C was determined in only about $75 \%$ of published studies. This does not allow PCES for the remaining 25\%. M-C can show the 
socially significant amount of behavior. Besides, M-C can provide intervention opportunities to the students until they reach the criterion and reduce performance discrepancies across subjects (Zimmerman \& Dibenedetto, 2008). Therefore, researchers and practitioners should be encouraged to identify $\mathrm{M}-\mathrm{C}$, even set an AP-C (for a more reasonable level) in the clinical and educational practices. Third, the real-world data used in the study may be one of its strengths. Nevertheless, the PCES methods were not tested with the methods (e.g., Monte Carlo) that produce controlled random data. Further research can test PCES by generated data as it may produce comprehensive results.

Fourth, autocorrelation and inclusion of data lengths in the effect sizes are considered important (e.g., Tarlow, 2017). However, these factors were ignored in the present study. Another issue is that PCES was tested with handling the data as a session, not time. This may impair trend prediction in representing organism behavior that develops over time. If parametric tests are employed for PCES, missing data can be attained, and problems such as autocorrelation can be solved. Fifth, limited data were used in comparison with the visual analysis, and the entire content used in the visual analysis was not assessed. Subsequent studies may examine the relationship of PCES with other variables ignored in this study.

Finally, the PCES methods are tested with only four nonoverlap-based methods. However, there are more than ten nonoverlap-based methods reported in the literature. In addition, the relationship of the PCES with the parametric (e.g., Allison \& Gorman, 1993; Huitema \& McKean, 2000; Pustejovsky et al., 2014; van den Noortgarte \& Onghena, 2003a; 2003b) or mean/distance-based methods (e.g., Carlin \& Costello, 2018; Hedges et al., 2012; Pustejovsky, 2018) was not examined in the present study. Therefore, further studies can examine the relationship between PCES methods and other nonoverlap methods, parametric indexes, or mean/distance-based methods. 


\section{References}

Allison, D. B., \& Gorman, B. S. (1993). Calculating effect sizes for meta-analysis: The case of the single case. Behavior Research and Therapy, 31(6), 621-631. https://doi.org/10.1016/0005-7967(93)90115-B

Aydin, O., \& Diken, I. H. (2020). Studies comparing augmentative and alternative communication systems (AAC) applications for individuals with autism spectrum disorder: a systematic review and meta-analysis. Education and Training in Autism and Developmental Disabilities, 55(2), 119-141.

Aydin, O., \& Yassikaya, M. Y. (2021). Validity and reliability analysis of the PlotDigitizer software program for data extraction from single-case graphs. Perspectives on Behavior Science. 1-19. Advance online puplication. https://doi.org/10.1007/s40614021-00284-0

Bambara, L. M., Cole, C. L., Chovanes, J., Telesford, A., Thomas, A., Tsai, S. C., ... \& Bilgili, I. (2018). Improving the assertive conversational skills of adolescents with autism spectrum disorder in a natural context. Research in Autism Spectrum Disorders, 48, 1-16. https://doi.org/10.1016/j.rasd.2018.01.002

Baer, D. M., Wolf, M. M., \& Risley, T. R. (1968). Some current dimensions of applied behavior analysis. Journal of Applied Behavior Analysis, 1(1), 91-97.

Bradshaw, J., Koegel, L. K., \& Koegel, R. L. (2017). Improving functional language and social motivation with a parent-mediated intervention for toddlers with autism spectrum disorder. Journal of Autism and Developmental Disorders, 47(8), 24432458. https://doi.org/10.1007/s10803-017-3155-8

Brossart, D. F., Laird, V. C., \& Armstrong, T. W. (2018). Interpreting Kendall's Tau and TauU for single-case experimental designs. Cogent Psychology, 5(1), 1-26. https://doi.org/10.1080/23311908.2018.1518687 
Brossart, D. F., Vannest, K. J., Davis, J. L., \& Patience, M. A. (2014). Incorporating nonoverlap indices with visual analysis for quantifying intervention effectiveness in single-case experimental designs. Neuropsychological Rehabilitation, 24(3-4), 464491. https://doi.org/10.1080/09602011.2013.868361

Busk, P. L., \& Serlin, R. C. (1992). Meta-analysis for single-case research. R. Kratochwil \& J. R. Levin (Ed.) Single-case research design and analysis: New directions for psychology and education inside (pp. 133-157). Hillsdale, NJ: Lawrence Erlbaum.

Carlin, M. T., \& Costello, M. S. (2018). Development of a distance-based effect size metric for single-case research: Ratio of distances. Behavior Therapy, 49(6), 981-994. https://doi.org/10.1016/j.beth.2018.02.005

Chen, L. T., Wu, P. J., \& Peng, C. Y. J. (2019). Accounting for baseline trends in intervention studies: Methods, effect sizes, and software. Cogent Psychology, 6(1), 1-20. https://doi.org/10.1080/23311908.2019.1679941

Cheng, Y., Huang, C. L., \& Yang, C. S. (2015). Using a 3D immersive virtual environment system to enhance social understanding and social skills for children with autism spectrum disorders. Focus on Autism and Other Developmental Disabilities, 30(4), 222-236. https://doi.org/10.1177\%2F1088357615583473

Fahmie, T. A., Iwata, B. A., \& Mead, S. C. (2016). Within-subject analysis of a prevention strategy for problem behavior. Journal of Applied Behavior Analysis, 49(4), 915-926. https://doi.org/10.1002/jaba.343

Ferron, J., Goldstein, H., Olszewski, A., \& Rohrer, L. (2020). Indexing effects in single-case experimental designs by estimating the percent of goal obtained. Evidence-Based Communication Assessment and Intervention, 14(1-2), 6-27. https://doi.org/10.1080/17489539.2020.1732024 
Fienup, D. M., \& Brodsky, J. (2017). Effects of mastery criterion on the emergence of derived equivalence relations. Journal of Applied Behavior Analysis, 50(4), 843-848. https://doi.org/10.1002/jaba.416

Fuller, J. L., \& Fienup, D. M. (2018). A preliminary analysis of mastery criterion level: Effects on response maintenance. Behavior Analysis in Practice, 11, 1-8. https://doi.org/10.1007/s40617-017-0201-0

Harrington, M., \& Velicer, W. F. (2015). Comparing visual and statistical analysis in singlecase studies using published studies. Multivariate Behavioral Research, 50(2), 162183. https://doi.org/10.1080/00273171.2014.973989

Hassan, M., Simpson, A., Danaher, K., Haesen, J., Makela, T., \& Thomson, K. (2018). An evaluation of behavioral skills training for teaching caregivers how to support social skill development in their child with autism spectrum disorder. Journal of Autism and Developmental Disorders, 48(6), 1957-1970. https://doi.org/10.1007/s10803-0173455-z

Hedges, L. G., Pustejovsky, J. E., \& Shadish, W. R. (2012). A standardized mean difference effect size for single-case designs. Research Synthesis Methods, 3(3), 224-239. https://doi.org/10.1002/jrsm.1052

Huitema, B. E., \& McKean, J. W. (2000). Design specification issues in time-series intervention models. Educational and Psychological Measurement, 60(1), 38-58. https://doi.org/10.1177/00131640021970358

Jamshidi, L., Heyvaert, M., Declercq, L., Fernández-Castilla, B., Ferron, J. M., Moeyaert, M., Beretvas, S. N., Onghena, P. \& Van den Noortgate, W. (2018). Methodological quality of meta-analyses of single-case experimental studies. Research in Developmental Disabilities, 79, 97-115. https://doi.org/10.1016/j.ridd.2017.12.016 
Kodak, T., Clements, A., Paden, A. R., LeBlanc, B., Mintz, J., \& Toussaint, K. A. (2015). Examination of the relation between an assessment of skills and performance on auditory-visual conditional discriminations for children with autism spectrum disorder. Journal of Applied Behavior Analysis, 48(1), 52-70. https://doi.org/10.1002/jaba.160

Kratochwill, T. R., Hitchcock, J., Horner, R. H., Levin, J. R., Odom, S. L., Rindskopf, D. M., \& Shadish, W. R. (2010). Single-case designs technical documentation. Retrieved from http://ies.ed.gov/ncee/wwc/pdf/wwc_scd.pdf

Kratochwill, T. R., Levin, J. R., Horner, R. H., \& Swoboda, C. M. (2014). Visual analysis of single-case intervention research: Conceptual and methodological issues. In T. R. Kratochwill \& J. R. Levin (Eds.), Single-case intervention research: Methodological and statistical advances (pp. 91-125). Washington, DC: American Psychological Association.

Lane, J. D., \& Gast, D. L. (2014). Visual analysis in single case experimental design studies: Brief review and guidelines. Neuropsychological Rehabilitation, 24(3-4), 445-463. https://doi.org/10.1080/09602011.2013.815636

Lerman, D. C., Hawkins, L., Hillman, C., Shireman, M., \& Nissen, M. A. (2015). Adults with autism spectrum disorder as behavior technicians for young children with autism: Outcomes of a behavioral skills training program. Journal of Applied Behavior Analysis, 48(2), 233-256. https://doi.org/10.1002/jaba.196

Maggin, D. M., \& Odom, S. L. (2014). Evaluating single-case research data for systematic review: A commentary for the special issue. Journal of School Psychology, 52, 237241. https://doi.org/10.1016/j.jsp.2014.01.002 
Maggin, D. M., Lane, K. L., \& Pustejovsky, J. E. (2017). Introduction to the special issue on single-case systematic reviews and meta-analyses. Remedial and Special Education, 38, 323-330. https://doi.org/10.1177/0741932517717043

Maggin, D. M., O'Keeffe, B. V., \& Johnson, A. H. (2011). A quantitative synthesis of methodology in the meta-analysis of single-subject research for students with disabilities: 1985-2009. Exceptionality, 19(2), 109-135.

https://doi.org/10.1080/09362835.2011.565725

Manolov, R. (2018). Linear trend in single-case visual and quantitative analyses. Behavior Modification, 42(5), 684-706. https://doi.org/10.1177/0145445517726301

Manolov, R., Gast, D. L., Perdices, M., \& Evans, J. J. (2014). Single-case experimental designs: Reflections on conduct and analysis. Neuropsychological Rehabilitation: An International Journal, 24, 634-660. https://doi.org/10.1080/09602011.2014.903199

Manolov, R., \& Vannest, K. J. (2019). A visual aid and objective rule encompassing the data features of visual analysis. Behavior Modification, 1-32. Advance online publication. https://doi.org/10.1177/0145445519854323

McDougale, C. B., Richling, S. M., Longino, E. B., \& O’Rourke, S. A. (2019). Mastery criteria and maintenance: a descriptive analysis of applied research procedures. Behavior Analysis in Practice. 1-9. Advance online publication. https://doi.org/10.1007/s40617-019-00365-2

Montes, C. C., Heinicke, M. R., \& Geierman, D. M. (2019). Awareness training reduces college students' speech disfluencies in public speaking. Journal of Applied Behavior Analysis, 52(3), 746-755. https://doi.org/10.1002/jaba.569

Parker, R. I., \& Vannest, K. J. (2009). An improved effect size for single case research: Nonoverlap of all pairs (NAP). Behavior Therapy, 40(4), 357-367. https://doi.org/10.1016/j.beth.2008.10.006 
Parker, R. I., Vannest, K. J., \& Brown, L. (2009). The improvement rate difference for singlecase research. Exceptional Children, 75(2), 135-150. https://doi.org/10.1177/001440290907500201

Parker, R. I., Vannest, K. J. \& Davis, J. L. (2011a). Effect size in single-case research: A review of nine nonoverlap techniques. Behavior Modification, 35(4), 303-322. https://doi.org/10.1177/0145445511399147

Parker, R. I., Vannest, K. J., Davis, J. L., \& Sauber, S. B. (2011b). Combining nonoverlap and trend for single-case research: Tau-U. Behavior Therapy, 42(2), 284-299. https://doi.org/10.1016/j.beth.2010.08.006

Pustejovsky, J. E. (2018). Using response ratios for meta-analyzing single-case designs with behavioral outcomes. Journal of School Psychology, 68, 99-112. https://doi.org/10.1016/j.jsp.2018.02.003

Pustejovsky, J. E., Hedges, L. V., \& Shadish, W. R. (2014). Design-comparable effect sizes in multiple baseline designs: A general modeling framework. Journal of Educational and Behavioral Statistics, 39(5), 368-393. https://doi.org/10.3102/1076998614547577

Putnam, B. C., \& Tiger, J. H. (2016). Assessing generative braille responding following training in a matching-to-sample format. Journal of Applied Behavior Analysis, 49(4), 751-767. https://doi.org/10.1002/jaba.330

Richling, S. M., Williams, W. L., \& Carr, J. E. (2019). The effects of different mastery criteria on the skill maintenance of children with developmental disabilities. Journal of Applied Behavior Analysis, 52(3), 701-717. https://doi.org/10.1002/jaba.580

Satsangi, R., Billman, R. H., \& Raines, A. R. (2020). Comparing video modeling to teacherled modeling for algebra instruction with students with learning disabilities. Exceptionality, 1-16. https://doi.org/10.1080/09362835.2020.1801436 
Scott, J., Lerman, D. C., \& Luck, K. (2018). Computer-based training to detect antecedents and consequences of problem behavior. Journal of Applied Behavior Analysis, 51(4), 784-801. https://doi.org/10.1002/jaba.495

Scruggs, T. E., Mastropieri, M. A., \& Casto, G. (1987). The quantitative synthesis of singlesubject research methodology and validation. Remedial and Special Education, 8(2), 24-33. https://doi.org/10.1177/074193258700800206

Shadish, W. R. (2014). Statistical analyses of single-case designs: The shape of things to come. Current Directions in Psychological Science, 23(2), 139-146. https://doi.org/10.1177/0963721414524773

Shadish, W. R., \& Sullivan, K. J. (2011). Characteristics of single-case designs used to assess intervention effects in 2008. Behavior Research Methods, 43(4), 971-980. https://doi.org/10.3758/s13428-011-0111-y

Shadish, W. R., Hedges, L. V., \& Pustejovsky, J. E. (2014). Analysis and meta-analysis of single-case designs with a standardized mean difference statistic: A primer and applications. Journal of School Psychology, 52(2), 123-147. https://doi.org/10.1016/j.jsp.2013.11.005

Shadish, W. R., Hedges, L. V., Horner, R. H., \& Odom, S. L. (2015). The role of betweencase effect size in conducting, interpreting, and summarizing single-case research. Retrieved from http://ies.ed.gov/

Shadish, W. R., Zelinsky, N. A., Vevea, J. L., \& Kratochwill, T. R. (2016). A survey of publication practices of single-case design researchers when treatments have small or large effects. Journal of Applied Behavior Analysis, 49(3), 656-673. https://doi.org/10.1002/jaba.308 
Sham, E., \& Smith, T. (2014). Publication bias in studies of an applied behavior-analytic intervention: an initial analysis. Journal of Applied Behavior Analysis, 47(3), 663-678. https://doi.org/10.1002/jaba.146

Sherrow, L. A., Spriggs, A. D., \& Knight, V. F. (2016). Using video models to teach students with disabilities to play the Wii. Focus on Autism and Other Developmental Disabilities, 31(4), 312-320. https://doi.org/10.1177/1088357615583469

Smith, J. D. (2012). Single-case experimental designs: A systematic review of published research and current standards. Psychological Methods, 17(4), 510-550. https://doi.org/10.1037/a0029312

Solomon, B. G., Howard, T. K., \& Stein, B. L. (2015). Critical assumptions and distribution features pertaining to contemporary single-case effect sizes. Journal of Behavioral Education, 24(4), 438-458. https://doi.org/10.1007/s10864-015-9221-4

Stocco, C. S., Thompson, R. H., Hart, J. M., \& Soriano, H. L. (2017). Improving the interview skills of college students using behavioral skills training. Journal of Applied Behavior Analysis, 50(3), 495-510. https://doi.org/10.1002/jaba.385

Tanious, R., De, T. K., Michiels, B., Van den Noortgate, W., \& Onghena, P. (2020). Assessing Consistency in Single-Case A-B-A-B Phase Designs. Behavior Modification, 44(4), 518-551. https://doi.org/10.1177/0145445519837726

Tanious, R., Onghena, P. (2019). Randomized single-case experimental designs in healthcare research: what, why, and how? Healthcare, 7(4), 1-19. https://doi.org/10.3390/healthcare7040143

Tarlow, K. R. (2017). An improved rank correlation effect size statistic for single-case designs: Baseline corrected Tau. Behavior Modification, 41(4), 427-467. https://doi.org/10.1177/0145445516676750 
Tekin-Iftar, E. (2018). Eğitim ve davranış bilimlerinde tek-denekli araştırmalar [Single-case research in education and behavior sciences] (2th ed.). Anı Yayınc1lik

Umbreit, J., Ferro, J., Liaupsin, C. J., \& Lane, K. L. (2007). Functional behavioral assessment and function-based intervention: An effective, practical approach. Upper Saddle River, NJ: Pearson.

van den Noortgarte, W., \& Onghena, P. (2003a). Combining single-case experimental data using hierarchical linear models. School Psychology Quarterly, 18(3), 325-346. https://doi.org/10.1521/scpq.18.3.325.22577

van den Noortgarte, W., \& Onghena, P. (2003b). Hierarchical linear models for the quantitative integration of effect sizes in single-case research. Behavior Research Methods, Instruments, and Computers, 35(1), 1-10. https://doi.org/10.3758/BF03195492

Vannest, K. J., \& Ninci, J. (2015). Evaluating intervention effects in single- case research designs. Journal of Counseling \& Development, 93(4), 403-411. https://doi.org/10.1002/jcad.12038

Vannest, K.J., Parker, R.I., Gonen, O., \& Adiguzel, T. (2016). Single Case Research: web based calculators for SCR analysis. (Version 2.0) [Web-based application]. College Station, TX: Texas A\&M University. Available from http://singlecaseresearch.org Wichnick-Gillis, A. M., Vener, S. M., \& Poulson, C. L. (2019). Script fading for children with autism: Generalization of social initiation skills from school to home. Journal of Applied Behavior Analysis, 52(2), 451-466. https://doi.org/10.1002/jaba.534

White, O. R., \& Haring, N. G. (1980). Exceptional teaching. Columbus, OH: Charles Merrill. Wolery, M. Busick, M., Reichow, B., \& Barton, E. E. (2010). Comparison of overlap methods for quantitatively synthesizing single-subject data. The Journal of Special Education, 44(1), 18-28. https://doi.org/10.1177/0022466908328009 
Wolf, M. M. (1978). Social validity: The case for subjective measurement or how aplied behavior analysis is finding its heart. Journal of Applied Behavior Analysis, 11(2), 203-214. https://doi.org/10.1901/jaba.1978.11-203

Zimmerman, B. J., \& Dibenedetto, M. K. (2008). Mastery learning and assessment: implications for students and teachers in an era of high-stakes testing. Psychology in the Schools, 45(3), 206-216. https://doi.org/10.1002/pits.20291 


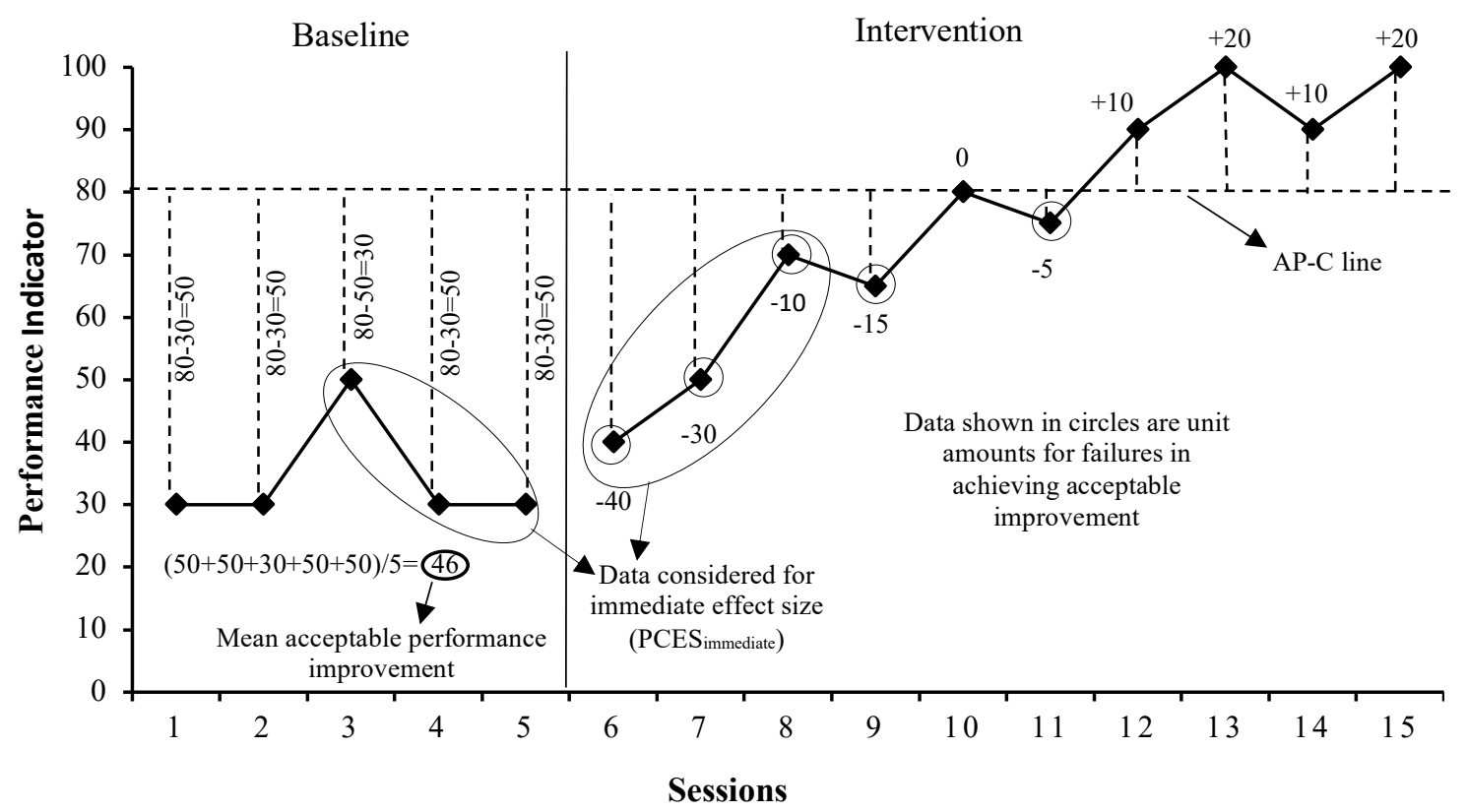

Figure 1a. Hypothetical data showing no baseline trend

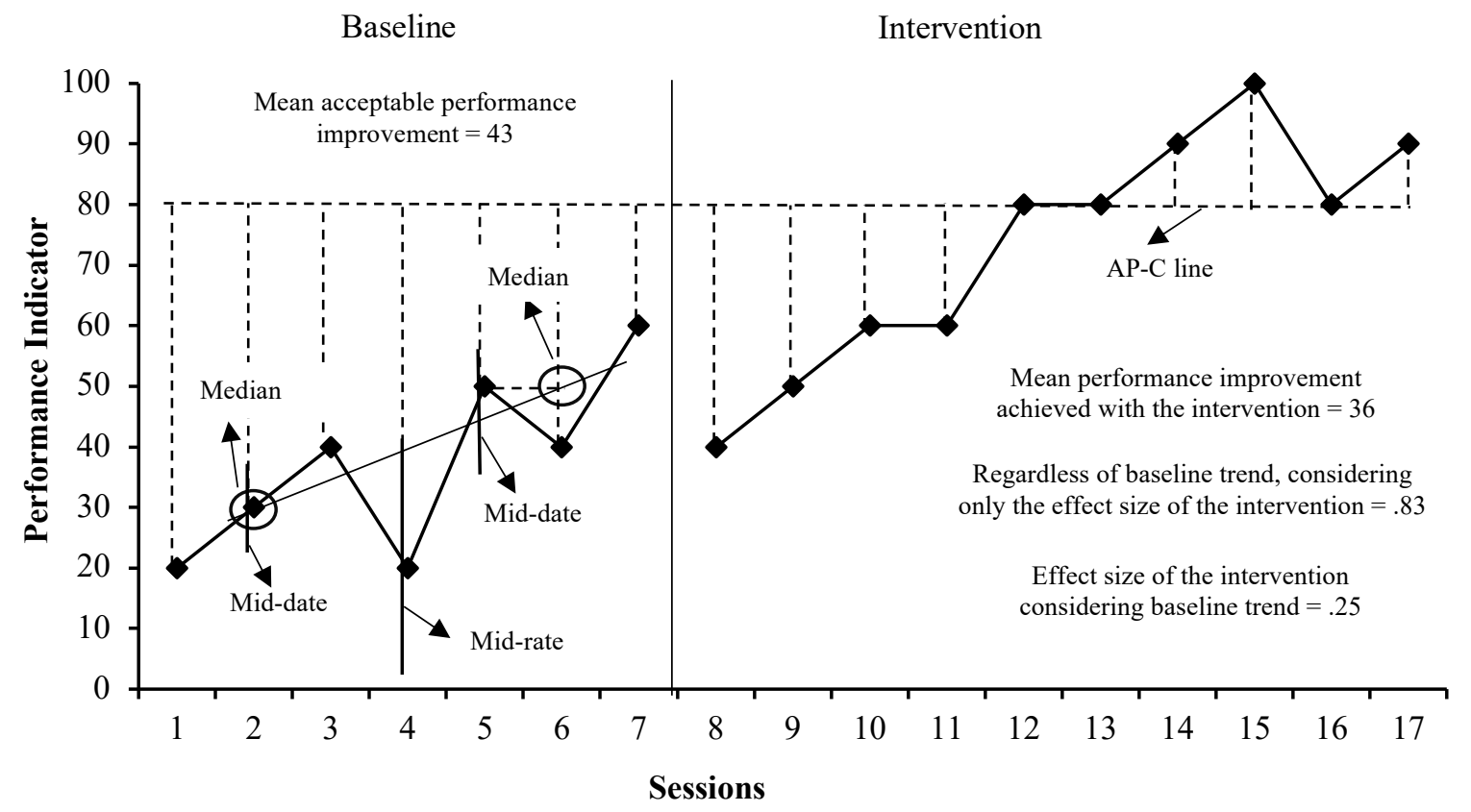

Figure 1b. Hypothetical data showing a positive baseline trend 

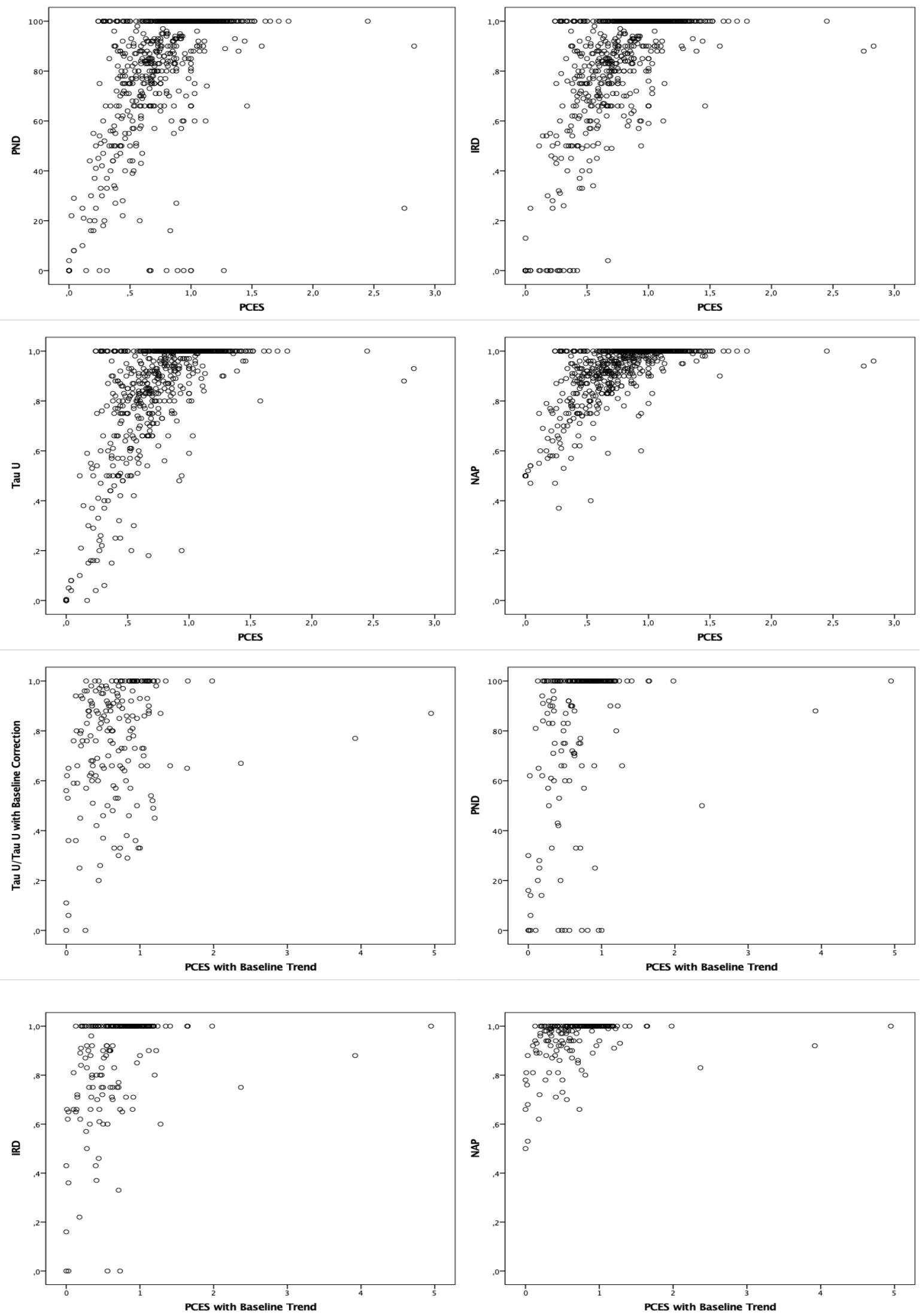

Figure 2. Scatterplot graphs showing relationship between PCES measurements and other methods 


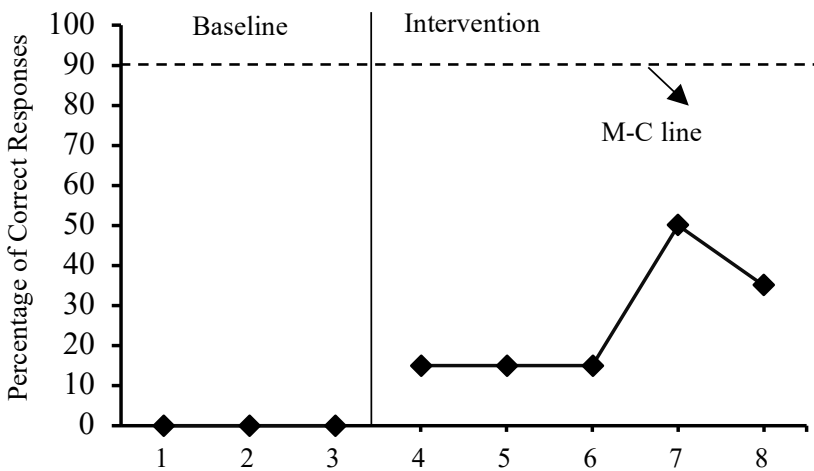

\section{Visual Analysis}

Mean level change: $26 \%$ increase

Stability of level change: $60 \%$ stable, $40 \%$ variable

Immediacy effect: $15 \%$ increase

Trend direction: Accelarating (targeted)

\section{Effect Size Indicators}

PND: $100 \%$; NAP: 1 ; IRD: 1 ; Tau- $U: 1$;

PCES: .29; PCES immediate: .17

Figure 3a. Data derived from Lerman et al (2015, p. 252, Fig. 5, Neal Child 6 Gen data)
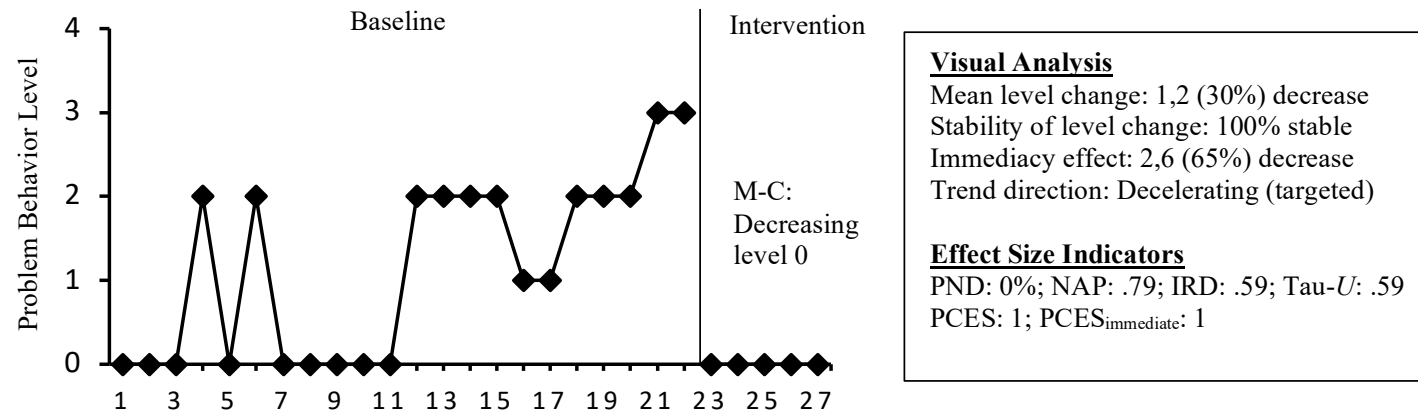

Mean level change: $1,2(30 \%)$ decrease

Stability of level change: $100 \%$ stable

Immediacy effect: 2,6 (65\%) decrease

Trend direction: Decelerating (targeted)

Effect Size Indicators

PND: 0\%; NAP: .79; IRD: .59; Tau-U: .59

PCES: 1 ; PCES immediate: 1

Figure 3b. Data derived from Fahmie et al (2016, p. 919, Fig. 2, B data)

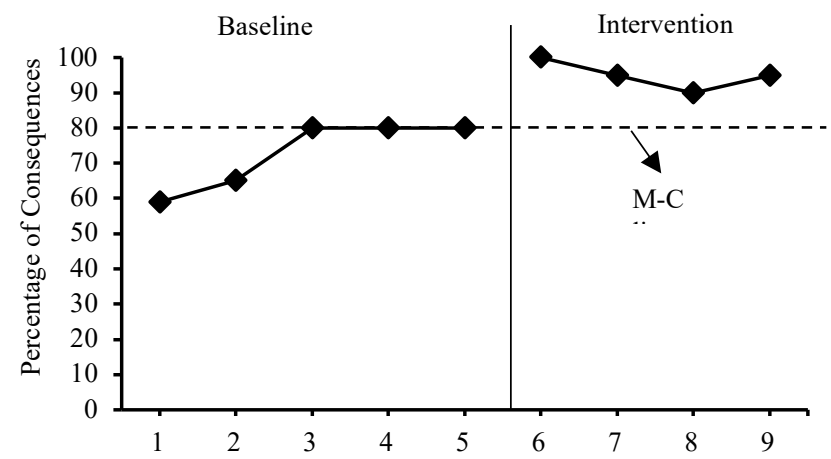

\section{Visual Analysis}

Mean level change: $22 \%$ increase

Stability of level change: $100 \%$ stable

Immediacy effect: $15 \%$ increase

Trend direction: Accelarating (targeted)

\section{Effect Size Indicators}

PND: $100 \%$; NAP: 1 ; IRD: 1 ; Tau- $U_{\mathrm{Bc}}: 65$

PCES Trend Two Data: 1; PCES Cumulative Trend: 1.5

$\mathrm{PCES}_{\beta_{\mathrm{t}}}: 1.64 ; \mathrm{PCES}_{\text {trend }}$ immediate $_{\text {in }}$ : Nan (The last three baseline

data equals mastery criterion)

Figure 3c. Data derived from Scott et al (2018, p. 795, Fig. 2, P17 data)

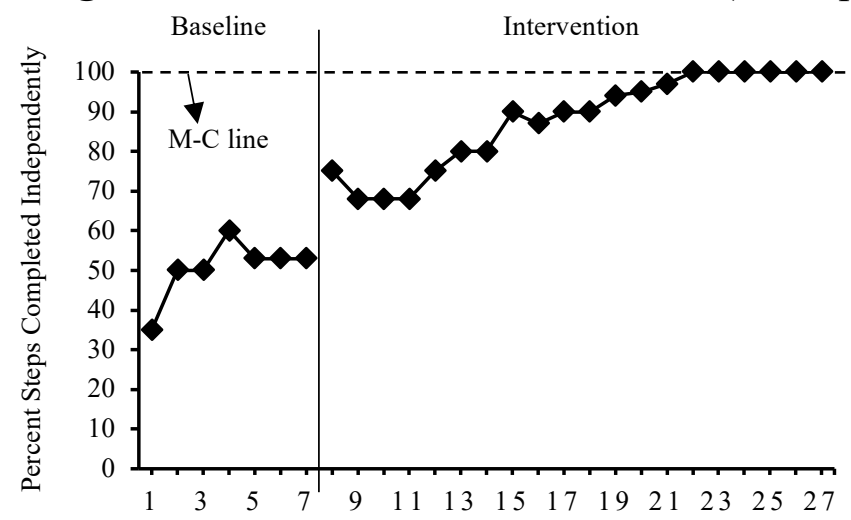

\section{Visual Analysis}

Mean level change: $38 \%$ increase

Stability of level change: $85 \%$ stable, $15 \%$ variable

Immediacy effect: $17 \%$ increase

Trend direction: Accelarating (targeted)

\section{Effect Size Indicators}

PND: $100 \%$; NAP: 1; IRD: 1 ; Tau- $U_{\mathrm{Bc}}: .92$

PCES Trend Three Data: .06; PCES Cumulative Trend: .21

PCES $_{\text {trend }}: .55 ;$ PCES $_{\text {trend }_{\text {immediate }}}: .28$

Figure 3d. Data derived from Sherrow et al (2016, p. 317, Fig. 1, Tony's data)

Figure 3. Selected graphs for visual analysis 
Table 1. Average results of the five effect size indices

\begin{tabular}{|c|c|c|c|}
\hline Effect Size Measures of Data without Baseline Trend & $M_{e s}$ & $S d_{e s}$ & $N$ \\
\hline Tau- $U$ & .87 & .22 & 804 \\
\hline PND & $85 \%$ & 25 & 806 \\
\hline NAP & .93 & .12 & 806 \\
\hline IRD & .86 & .23 & 805 \\
\hline PCES & .82 & .33 & 801 \\
\hline Total valid comparision data number for the five methods & - & - & 800 \\
\hline \multicolumn{4}{|l|}{ Effect Size Measures of Data with Baseline Trend } \\
\hline Tau- $U / \mathrm{Tau}-U_{\mathrm{Bc}}$ & .74 & .25 & 205 \\
\hline PND & $78 \%$ & 33 & 206 \\
\hline NAP & .94 & .10 & 206 \\
\hline IRD & .84 & .23 & 205 \\
\hline $\mathrm{PCES}_{\text {trend }}$ & .71 & .54 & 191 \\
\hline Total valid comparision data number for the five methods & - & - & 190 \\
\hline
\end{tabular}

Note: $\mathrm{M}_{\mathrm{es}}=$ Mean effect size, $\mathrm{Sd}_{\mathrm{es}}=$ Standard deviation of effect size, $\mathrm{N}=$ Tiers (AB phases) number included in the correlation analysis 
Table 2. Correlation matrix tables

Table 2a. Correlation matrix for the data without baseline trend

\begin{tabular}{llllll}
\hline Effect Size Methods & PCES & NAP & IRD & PND & Tau- $U$ \\
\hline PCES & 1 & & & & \\
NAP & .63 & 1 & & & \\
IRD & .62 & .98 & 1 & & \\
PND & .55 & .98 & .98 & 1 & 1 \\
Tau- $U$ & .60 & .99 & .98 & .97 & \\
\hline
\end{tabular}

Note: $p<.0001$ for all

Table 2b. Correlation matrix for the data with baseline trend

\begin{tabular}{|c|c|c|c|c|c|}
\hline Effect Size Methods & $\mathrm{PCES}_{\beta_{\mathrm{t}}}$ & NAP & IRD & PND & Tau- $U /$ Tau- $U_{B C}$ \\
\hline $\mathrm{PCES}_{\text {trend }}$ & 1 & & & & \\
\hline NAP & .38 & 1 & & & \\
\hline IRD & .40 & .97 & 1 & & \\
\hline PND & .35 & .96 & .96 & 1 & \\
\hline Tau- $U /$ Tau- $U_{\mathrm{Bc}}$ & .38 & .53 & .49 & .50 & 1 \\
\hline
\end{tabular}

Note: Tau- $U_{\mathrm{Bc}}=$ Tau- $U$ with baseline correction (If the baseline data contrast $\geq .4$, Tau- $U_{\mathrm{Bc}}$ was used), $p<.0001$ for all. 
Table 3. Percentile distribution ranks for PCES and the four nonoverlap indices

Table 3a. Key percentile ranks for effect size indices without baseline trend

\begin{tabular}{llllll}
\hline Percentile & \multicolumn{5}{c}{$95 \%$ Confidence Intervals (Lower, Upper) } \\
\cline { 2 - 6 } Rank & PCES & NAP & IRD & PND & Tau-U \\
\hline 10 th & $.39(.36, .42)$ & $.78(.75, .82)$ & $.58(.51, .63)$ & $51.1(46.2,60)$ & $.57(.50, .65)$ \\
25 th & $.61(.58, .65)$ & $.91(.90, .92)$ & $.80(.77, .83)$ & $80(75,83)$ & $.83(.80, .85)$ \\
50 th & $.85(.81, .86)$ & $1(1,1)$ & $1(1,1)$ & $85(81,86)$ & $1(1,1)$ \\
75 th & $1.02(1,1.06)$ & $1(1,1)$ & $1(1,1)$ & $100(100,100)$ & $1(1,1)$ \\
90 th & $1.17(1.15,1.20)$ & $1(1,1)$ & $1(1,1)$ & $100(100,100)$ & $1(1,1)$
\end{tabular}

Table 3b. Key percentile ranks for effect size indices with baseline trend

\begin{tabular}{llllll}
\hline Percentile & \multicolumn{5}{c}{$95 \%$ Confidence Intervals (Lower, Upper) } \\
\cline { 2 - 6 } Rank & PCES trend & NAP & IRD & PND & Tau $U /$ Tau- $U_{B c}$ \\
\hline 10 th & $.20(.13, .28)$ & $.82(.78, .89)$ & $.62(.50, .66)$ & $25.3(6.8,50.3)$ & $.42(.33, .52)$ \\
25 th & $.40(.33, .47)$ & $.94(.90, .96)$ & $.75(.71, .84)$ & $71.75(62,83)$ & $.63(.57, .66)$ \\
50 th & $.67(.60, .73)$ & $1(.99,1)$ & $1(.96,1)$ & $100(96.5,100)$ & $.83(.78, .87)$ \\
75 th & $.92(.86,1)$ & $1(1,1)$ & $1(1,1)$ & $100(100,100)$ & $.96(.93,1)$ \\
90 th & $1.12(1.06,1.19)$ & $1(1,1)$ & $1(1,1)$ & $100(100,100)$ & $1(1,1)$ \\
\hline
\end{tabular}


Table 4. Cutoff scores and interpretations for PCES calculations

\section{Cutoff Scores}

\begin{tabular}{lll}
\cline { 2 - 2 } Interpretations & PCES & PCES trend \\
\hline High effect & $\geq 1.17$ & $\geq 1.12$ \\
Effective & $1.17<\geq 1.02$ & $1.12<\geq .92$ \\
Moderate effect & $1.02<\geq .85$ & $.92<\geq .67$ \\
Small effect & $.85<\geq .61$ & $.67<\geq .40$ \\
Very small effect & $.61<>.39$ & $.40<>.20$ \\
Ineffective & $\leq .39$ & $\leq .20$ \\
\hline
\end{tabular}




\section{Appendix: $C_{t}$ Calculation Equations}

$\mathrm{n}_{\mathrm{A}}$ : Number of data points in the baseline phase

$\mathrm{n}_{\mathrm{B}}$ : Number of data points in the intervention phase

$\mathrm{n}_{\mathrm{i}}$ : Number of baseline data with trend taken into consideration (min. 2 data points, max. 4)

$y$ : Each value (from $\mathrm{k}$ to $n_{A}$, from $i$ to $n_{A}$ )

$b_{n_{i}}$ : Baseline trend which is moved up to $\mathrm{n}_{\mathrm{i}}$ data points

$\mathrm{C}_{\mathrm{t}}$ : Cumulative trend manipulating the intervention

$\mathrm{M}_{\mathrm{c}}$ : Mastery criterion

Baseline trend coefficient;

$b_{n_{i}}=\left|\frac{\frac{\sum_{k=\left(n_{A}-n_{i}+1\right)}^{n_{A}} y_{k}}{n_{i}}-\frac{\sum_{i=1}^{n_{A}} y_{i}}{n_{A}}}{M_{C^{-}}-\frac{\sum_{i=1}^{n_{A}} y_{i}}{n_{A}}}\right|$

(Equation A)

First, if $n_{B}$ is divided by $n_{i}$ without a remainder, the following equation is obtained;

$\frac{\mathrm{n}_{\mathrm{B}}}{\mathrm{n}_{\mathrm{i}}}=a$

(Equation B)

Cumulative trend according to equations $\mathrm{A}$ and $\mathrm{B}$;

$\mathrm{C}_{\mathrm{t}}=\frac{b_{n_{i}}(a+1)}{2}$

(Equation C)

Second, if $n_{B}$ is divided by $n_{i}$ with a remainder, $e$ is the remainder, the following equation is obtained;

$\frac{\mathrm{n}_{\mathrm{B}}}{\mathrm{n}_{\mathrm{i}}}=a+\frac{e}{\mathrm{n}_{\mathrm{i}}}$ (Equation D)

Cumulative trend according to equations $\mathrm{A}$ and $\mathrm{D}$;

$\mathrm{C}_{\mathrm{t}}=\frac{b_{n_{i}}(a+1)\left(n_{i}{ }^{2} a+2 e\right)}{2 n_{i}\left(n_{i} a+e\right)}$

(Equation E) 
Note: The maximum possible trend should be considered in the intervention. Therefore, the equations above are appropriate for calculations that do not exceed the maximum possible trend. However, they are not appropriate for long datasets since the maximum possible trend exceeds. Instead of these, the cumulative trend should be calculated by following the long equation:

$\mathrm{C}_{\mathrm{t}}=\frac{b_{n_{i}} n_{i}+2 b_{n_{i}} n_{i}+\cdots+k b_{n_{i}} n_{i}+\cdots+k b_{n_{i}} n_{i}\left(\text { or } k b_{n_{i}} e^{2} / n_{i}\right)}{\mathrm{n}_{\mathrm{B}}}$

If the remainder from $\frac{\mathrm{n}_{\mathrm{B}}}{\mathrm{n}_{\mathrm{i}}}$ is zero, $k b_{n_{i}}$ coefficient can be calculated by multiplying $n_{i}$ as constant. If there is a remainder, the last $k b_{n_{i}}$ coefficient includes trend as much as the remaining data point number $\left(\frac{k b_{n_{i}} e}{n_{i}}\right)$ and this trend is multiplied to calculation as much as $e$. 